\title{
Physical and Biological Determinants of the Fabrication of Molluscan Shell Microstructures
}

\author{
Antonio G. Checa ${ }^{1,2 *}$ \\ ${ }^{1}$ Department of Stratigraphy and Paleontology, University of Granada, Granada, Spain, ${ }^{2}$ Instituto Andaluz de Ciencias de la \\ Tierra, Consejo Superior de Investigaciones Cientificas-University of Granada, Granada, Spain
}

Molluscs are grand masters in the fabrication of shells, because these are composed of the largest variety of microstructures found among invertebrates. Molluscan microstructures are highly ordered aggregates of either calcite or aragonite crystals with varied morphologies and three-dimensional arrangements. Classically, every aspect of the fabrication of microstructural aggregates is attributed to the action of proteins. There was, however, only direct evidence that the mineral phase, and indirect evidence that nucleation and the crystal shape, are determined by the types of soluble proteins. Some authors imply that crystal competition may also play a role. In addition, the fabrication

OPEN ACCESS

Edited by:

Pei-Yuan Qian,

Hong Kong University of Science and Technology, Hong Kong

Reviewed by:

Gary H. Dickinson,

The College of New Jersey,

United States

Adam Michael Reitzel, University of North Carolina at Charlotte, United States

*Correspondence: Antonio G. Checa acheca@ugr.es

Specialty section: This article was submitted to Marine Molecular Biology and Ecology,

a section of the journal

Frontiers in Marine Science

Received: 29 January 2018 Accepted: 12 September 2018 Published: 26 September 2018

Citation:

Checa AG (2018) Physical and Biological Determinants of the Fabrication of Molluscan Shell Microstructures.

Front. Mar. Sci. 5:353. doi: 10.3389/fmars.2018.00353 of intergranular organic matrices typical of some microstructures (nacre, columnar prismatic) cannot have a protein-based explanation. Over the last decade I and collaborators have been applying a holistic view, based on analyzing and interpreting the features of both the organic (mantle, extrapallial space, periostracum, organic matrices) and inorganic (crystallite morphology, arrangement, and crystallography) components of the biomineralization system. By interpreting them on biophysical principles, we have accumulated evidence that, in addition to the activity of proteins, other mechanisms contribute in an essential way to the organization of molluscan microstructures. In particular, we have identified processes such as: (1) crystal nucleation on preformed membranes, (2) nucleation and growth of crystals between and within self-organized membranes, (3) active subcellular processes of contact recognition and deposition. In summary, besides the activity of organic macromolecules, physical (crystal competition, self-organization) and/or biological (direct cellular activity) processes may operate in the fabrication of microstructures. The balance between the physical and biological determinants varies among microstructures, with some being based exclusively on either physical or biological processes, and others having a mixed nature. Other calcifying invertebrates (e.g., corals, cirripeds, serpulids) secrete microstructures that are very similar to inorganic crystal aggregates, and only some brachiopods and, to a lesser extent, bryozoans may have secretory abilities comparable to those of molluscs. Here I provide a new perspective, which may allow microstructures to be understood in terms of evolutionary constraints, to compare the secretional abilities among taxa, and even to evaluate the probability of mimicking microstructures for the production of functional synthetic materials.

Keywords: molluscs, shells, microstructures, biomineralization, calcium carbonate, self-organization, mantle cells, crystallography 


\section{INTRODUCTION}

Molluscs are, after the Arthropoda, the most diverse marine phylum of invertebrates, with an imprecise known diversity between 41,000 and 53,000 species (Appeltans et al., 2012). An essential element of their basic body plan is a calcareous shell, which can be unique (gastropods, monoplacophorans and scaphopods), twofold (bivalves) or eightfold (polyplacophorans). Aplacophorans only secrete aragonitic spicules embedded in a peripheral cuticle. During the course of evolution within the different classes, some groups have reduced, internalized or even suppressed the shell (e.g., coleoidean cephalopods cuttlefishes, squids, octopuses-, opisthobranch and pulmonate gastropods).

Mollusc shells are organo-mineral biocomposites, in which the mineral part constitutes $95-99 \%$ of the shell weight while the organic fraction makes up 0.1-5\% (Hare and Abelson, 1965). Exceptional values of up to $16 \%$ organic matter have been recorded in the calcitic columnar prismatic layers of the pteriomorph bivalve Pinna nobilis (Checa et al., 2016a). Despite its small volumetric representation, the organic fraction is extremely complex, with hundreds of proteins, polysaccharides and lipids, which can differ according to molluscan group. The mineral part of the molluscan shell is typically made entirely of calcium carbonate, in particular, calcite and/or aragonite. Vaterite, a third anhydrous polymorph of calcium carbonate, is only found exceptionally (Ma and Lee, 2006; Wehrmeister et al., 2007; Spann et al., 2010; Nehrke et al., 2012). Amorphous calcium carbonate (ACC) has been encountered within the shells of some bivalves and gastropods (Nudelman et al., 2007; Baronnet et al., 2008; Macías-Sánchez et al., 2017), but it is regarded as a transient precursor phase. Today it is known that a small fraction of the initial ACC can be permanently stabilized within the biominerals (Macías-Sánchez et al., 2017, and references therein).

The shell of molluscs comprises an outer, entirely organic or sparsely mineralized layer (the periostracum) and a series of superposed shell layers. Some groups exceptionally produce deposits over the shell exterior, such as the external crusts on the shells of the venerid bivalves Granicorium and Samarangia, composed of cemented sediment grains (Taylor et al., 1999), or the inductural deposits, present in some cardiid bivalves and common in cypraeid gastropods (Checa and Salas, 2017). Shell layers are monomineralic, but molluscs are able to superpose layers with the two mineralogies. When calcite is present, it is typically restricted to the outer shell layer, or it may comprise all subperiostracal shell layers except for myostracal prisms and ligament fibers, which are invariably aragonitic. Shell layers are made of crystals with varied and recurrent morphologies and 3-D configurations and arrangements, which define the different microstructures. In general, it is recognized that shell biomineralization in the Mollusca is largely biologically controlled (i.e., the organism directs the nucleation, growth, morphology, orientation and location of the biominerals), rather than merely biologically mediated (i.e., biominerals precipitate as a result of metabolic activities on cell surfaces, with little or no control on the morphology and organization of biominerals) (Lowenstam, 1981; Mann, 1983). According to the range of microstructures and their degree of sophistication, molluscs are unrivaled among invertebrates.

The number of molluscan microstructures is limited (Carter et al., 2012). Microstructural patterns, in general, depend on the mineralogy (Figure 1). The most typical calcitic microstructures are columnar prismatic, granular prismatic, fibrous, foliated, chalk and crossed-foliated. The most characteristic aragonitic microstructures are columnar prismatic, fibrous prismatic, lamellar, nacre and crossed lamellar. While every microstructure has a certain morphological range, no transitions exist between microstructures. This suggests some kind of crystallographic/fabricational constraints. At the same time, homeomorphic microstructures (e.g., nacre, crossed-lamellar or foliated) have developed independently in and within the different classes. The most dramatic examples of convergence are nacre, which appeared independently in Bivalvia, Gastropoda, Cephalopoda, and Monoplacophora (Vendrasco et al., 2011), and the crossed lamellar microstructure, which developed separately in all extant molluscan classes with the exception of the Cephalopoda and Aplacophora. Certain extinct Monoplacophora (i.e., the Bellerophontida), and the extinct molluscan classes Hyolitha (but see Moysiuk et al., 2017, for a lophophorate affinity of hyoliths) and Rostroconchia also developed crossed-lamellar microstructures independently.

One of the most distinctive features of microstructures is their high degree of morphological and crystallographic ordering. This is best appreciated in the construction of pole figures derived from diffraction methods (X-ray diffraction, XRD, or electron back-scatter diffraction, EBSD). Pole figures plot the distribution (usually as density curves) of the poles of particular faces or crystallographic directions in stereographic projection. Concentrations of values within one or several maxima indicate that the different crystals making up the aggregate are cooriented along a given crystallographic direction. The degree of alignment is inversely related to the spread of the maxima. All microstructures hitherto analyzed display a defined maximum for the $c$-axis of either calcite or aragonite, which indicates that the $c$-axes of crystals are relatively co-oriented. In some cases, the maxima for the rest of the axes are ring-like. This pattern is the so-called fiber texture, with the $c$-axis as the fiber axis. This texture is displayed by aragonitic and calcitic prismatic, aragonitic granular prismatic microstructures, and gastropod nacre (Checa and Salas, 2017). Other microstructures display a higher degree of ordering, with all axes co-oriented. This is called a sheet texture and is found in bivalve and Nautilus nacre (Hedegaard and Wenk, 1998; Chateigner et al., 2000), the crossed lamellar layers of all extant molluscan classes (Hedegaard and Wenk, 1998; Chateigner et al., 2000; Almagro et al., 2016), the foliated aragonite of monoplacophorans (Checa et al., 2009b,c), the foliated calcite of bivalves (Checa et al., 2007), and the fibrous calcite of Mytilidae (Checa et al., 2014a). A rare case is that in which there are two maxima for the $c$-axis, as in many instances of crossed-lamellar microstructures (Almagro et al., 2016).

Prior to or at the initiation of the postlarval stage, shell secretion is carried out by the mantle, which has a thin external epithelium composed of a single layer of cells. The outer surface of the mantle epithelium is in contact with the internal (growth) 


\section{CALCITE}
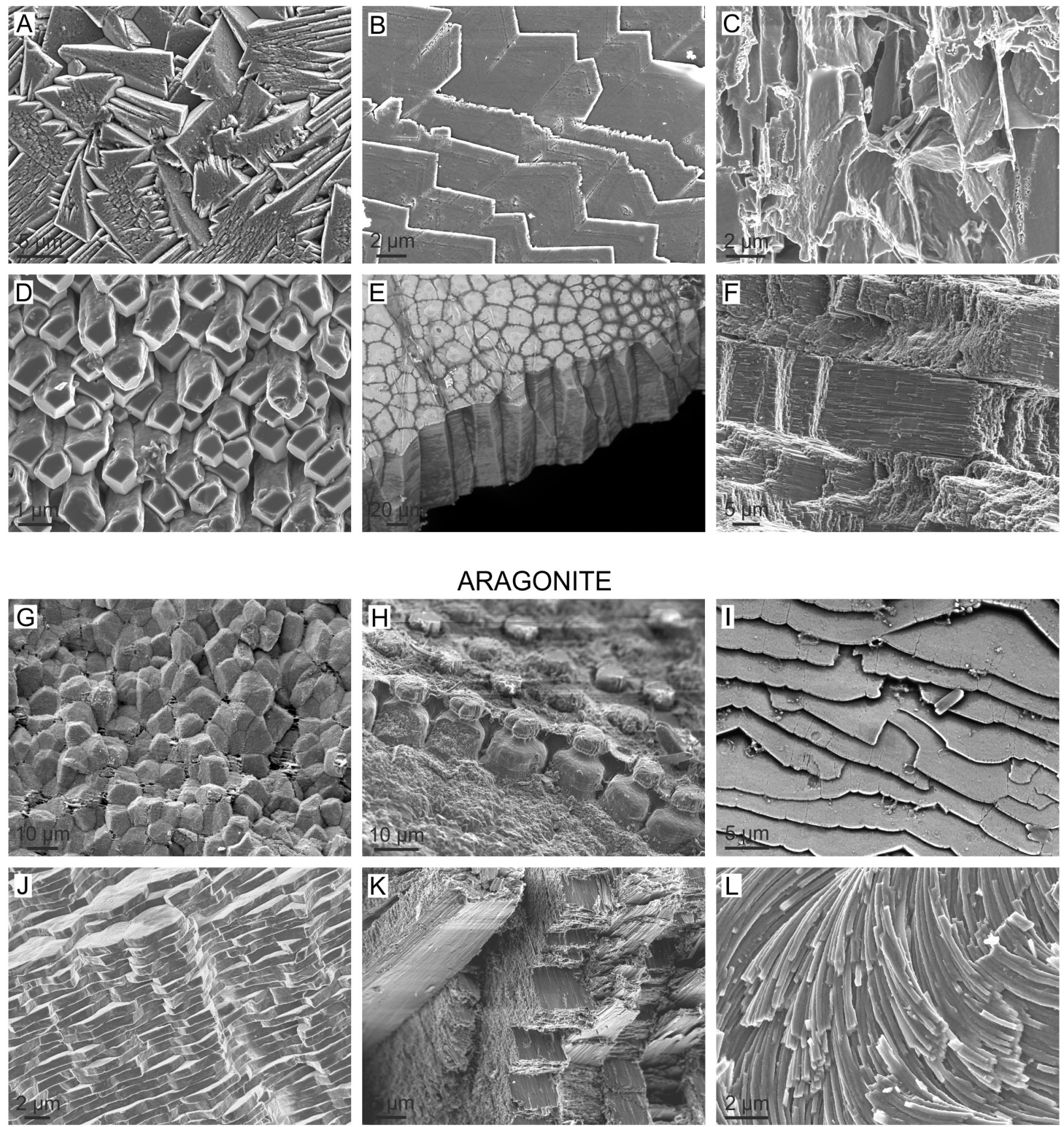

FIGURE 1 | The high diversity of molluscan microstructures, illustrated with selected representative calcitic and aragonitic cases. (A) Granular (rhombohedral) calcite. Outer layer of the patellogastropod Cellana toreuma. (B) Foliated calcite. Bivalve Anomia ephippium. (C) Chalk. Bivalve Crassostrea angulata. (D) Anvil-type fibrous calcite. Outer layer of the bivalve Mytilus chilensis. (E) Columnar prismatic calcite. Outer layer of the bivalve Pinctada margaritifera. (F) Crossed-foliated. Middle layer of the patellogastropod Scutellastra tabularis. (G) Granular prismatic aragonite. Outer layer of the bivalve Entodesma navicula. (H) Columnar prismatic aragonite. Outer layer of the bivalve Neotrigonia lamarckii. (I) Foliated aragonite. Inner layer of the monoplacophoran Rokopella euglypta. (J) Nacre. Internal layer of the bivalve Neotrigonia bednalli. (K) Crossed lamellar. Internal layer of the caenogastropod Semicassis granulata. (L) Helical fibrous aragonite. Opisthobranch gastropod Cuvierina columnella.

surface of the shell. The mantle edge is divided into several folds (usually three, but up to five). Shell secretion begins with the formation of the periostracum, at the base of a groove between the outer and the middle mantle folds, called the periostracal groove. The calcified part of the shell begins to be secreted more or less at the edge of outer mantle fold. At this position, the periostracum 


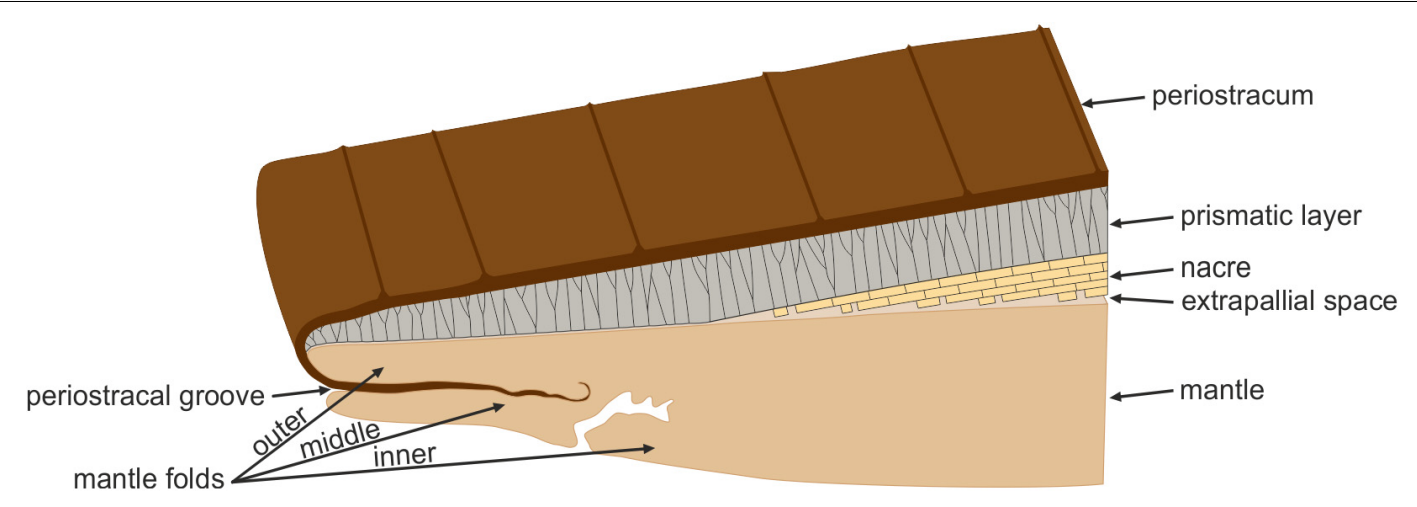

FIGURE 2 | The bivalve mollusc biomineralization system. The mantle is separated from the shell by the extrapallial space. The first component to be secreted is the periostracum, at the groove between the outer and middle mantle folds. The mineral shell layers are secreted by the outer surface of the outer mantle fold. The archetypical prismato-nacreous shell is used for the illustration.

is reflected backward toward the dorsum and the first crystals begin to be secreted below the periostracum, or, occasionally, within a not-yet-tanned internal periostracum (Checa and Salas, 2017). In either case, the periostracum seals the biomineralization compartment between mantle and shell. This process is depicted in Figure 2.

The space between the growing shell and the adjacent mantle epithelium is a thin fluid film called the extrapallial space, across which the transference of mineral and organic components from the mantle to the shell takes place (Figure 2). The fluid filling in the extrapallial space is the extrapallial fluid. The extrapallial space also contains inorganic (Wilbur and Saleuddin, 1983), as well as organic compounds, including amino acids (Wada and Fujinuki, 1976; Misogianes and Chasteen, 1979), proteins (Kobayashi, 1964a,b; Pietrzak et al., 1973; Misogianes and Chasteen, 1979), mucopolysaccharides (Kobayashi, 1964b; Crenshaw, 1972; Misogianes and Chasteen, 1979) and organic acids (Wilbur and Simkiss, 1968). This organic fraction is presumably incorporated into the shell as extra- and intracrystalline organic fractions.

There is very little evidence available about the dimensions of the extrapallial space. The exceptional transmission electron microscopy (TEM) micrographs on sections of the shell-mantle complex of the pterioid bivalve Pinctada radiata provided by Bevelander and Nakahara (1969), Nakahara and Bevelander (1971), and Nakahara (1991) show that in nacre the approximate thickness of the extrapallial space is $\sim 100 \mathrm{~nm}$ (Figure 3A), whereas in prismatic layers, the thickness can be less precisely estimated, but is submicrometric. It is assumed that the mantleshell relationship was not altered during sample preparation. The thickness of the extrapallial space could be precisely estimated by Checa et al. (2014b) in the intraperiostracal mineralized bosses of the aragonitic prisms of the bivalve Neotrigonia. Since these bosses were formed within a deep spiral-shaped periostracal groove (Figure 3B), it is highly unlikely that the relative positions and dimensions of crystals and the mantle were affected during ultramicrotome sectioning for TEM. The observed thickness of the extrapallial space below the forming bosses is $c a .100 \mathrm{~nm}$ (Figures 3C,D), which is in agreement with the figures derived from Bevelander and Nakahara's illustrations of nacre. The fact that the boundaries between shell layers with different microstructures (and, sometimes, also different mineralogies) are so well defined, argues for a submicron thick extrapallial space, which imposes strict limits on the lateral diffusion of organic and inorganic components.

The organic fraction of the major shell layers is mainly composed of proteins, acidic polysaccharides and chitin (presumably the $\beta$ polymorph) (Lowenstam and Weiner, 1989; Levi-Kalisman et al., 2001; Pereira-Mouriès et al., 2002; Weiner and Dove, 2003). In nacre and in calcitic and aragonitic columnar prismatic layers, part of the organic fraction assembles into an extracrystalline 3-D organic matrix framework. Some other macromolecules are absorbed by crystals during growth, forming an intracrystalline organic phase (Berman et al., 1993; Weiner and Addadi, 1997). In 1996, two independent research groups demonstrated that polymorph secretion is controlled by macromolecules associated with either calcitic or aragonitic shell layers. In particular, Belcher et al. (1996) precipitated calcium carbonate in the presence of soluble proteins extracted from either calcitic or aragonitic shells from a variety of taxa, preabsorbed on a substrate of squid chitin and silkworm fibroin. They consistently found coincidence of the precipitated polymorph with that of the original shell. Falini et al. (1996) obtained similar results, although they concluded that crystal nucleation and orientation do not require pre-organized organic matrices.

There is presently a significant amount of studies aiming at isolating and characterizing the soluble molluscan shell proteins, despite their low representation (0.03-0.5\% weight). Good reviews have been provided by Cusack and Freer (2008) and Marin et al. (2008). Highly acidic proteins are preferentially associated with calcitic shells and, due to the preponderance of negatively charged Asp-rich residues, are Ca-binding proteins. They are particularly suited for control over crystal growth and interaction with crystal faces. Nacreins and pearlins are intermediate proteins extracted from nacre and display a diversity of functions, such as Ca-binding, carbonic anhydrase activity and inhibition of calcium carbonate precipitation. Basic proteins have 

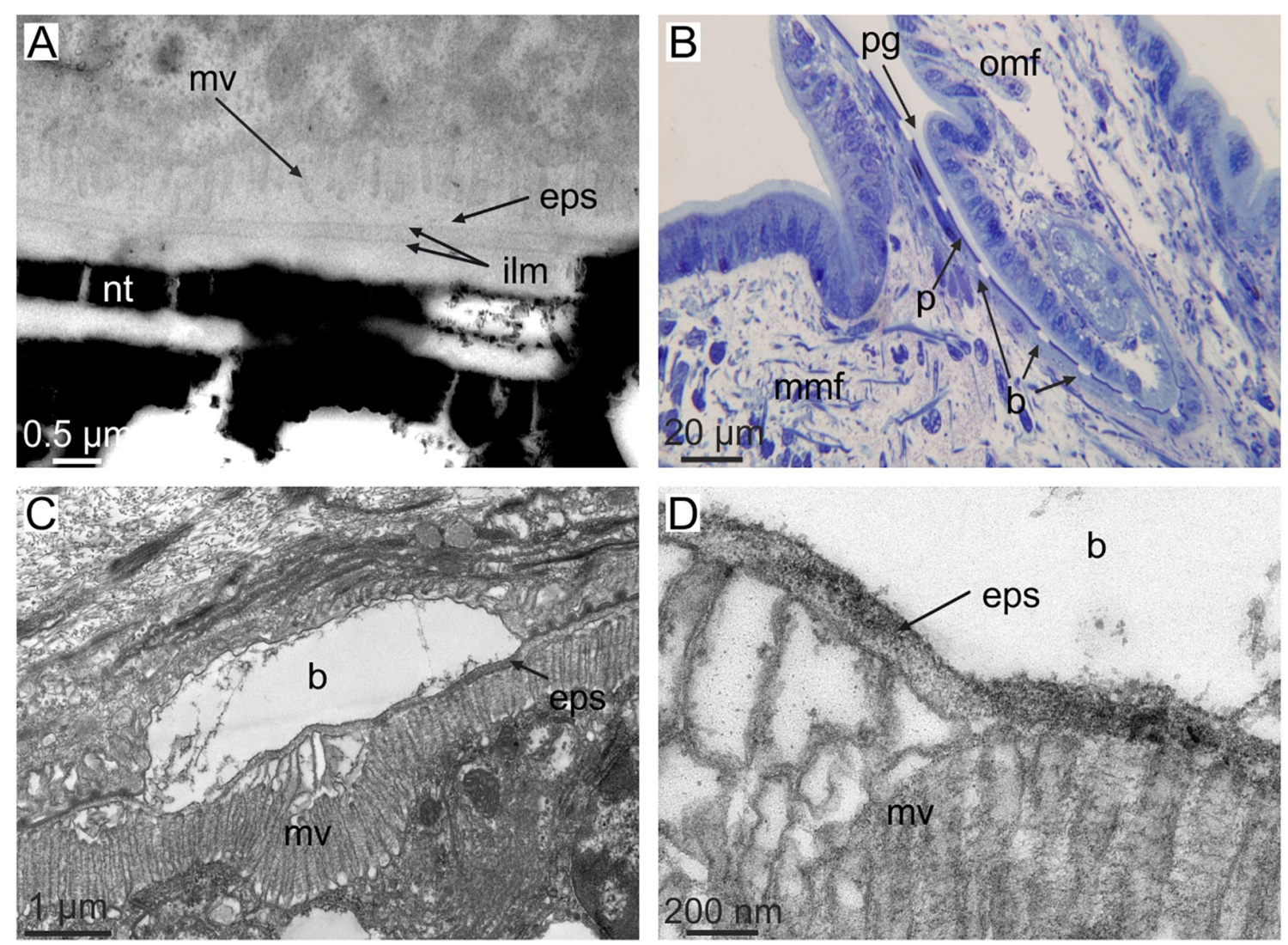

FIGURE 3 | The dimensions of the extrapallial space in bivalves. (A) Section through the shell and mantle of Pinctada fucata. Note the short distance between microvilli and the forming interlamellar membranes (i.e., the extrapallial space). Original material from H. Nakahara. (B-D) Sections through the mantle edge (B) and periostracal groove (C,D) of Neotrigonia margaritacea (decalcified sample). The view in (B) shows the periostracum, together with mineral bosses of the prisms being formed within the periostracal groove. (C,D) Show the relative positions of the crystalline bosses and the cell microvilli. The close-up view in (D) permits estimating an approximate thickness of the extrapallial space of ca. $100 \mathrm{~nm}$. b, boss; mv, cell microvilli; eps, extrapallial space; ilm, interlamellar membrane; mmf, middle mantle fold; nt, nacre tablet; omf, outer mantle fold; p, periostracum; pg, periostracal groove. (C,D) Modified from Checa et al. (2014b).

been extracted both from calcitic and aragonitic layers. Some of them display interesting in vitro activities, like the nucleation of calcium carbonate (perlucin) or its inhibition (perlwappin). In summary, there is presently reliable, direct evidence that proteins control the polymorph. In vitro assays also suggest that proteins promote crystal nucleation and, by attaching to particular crystal faces, they are likely to control the shapes of crystals. However, the molecular aspects of the shell building process are still far from fully understood, because soluble and insoluble organic molecules synergistically control the nucleation, growth, polymorphism, and orientation of biomineral deposition. For this reason, it is difficult to mimic the biomineralization process and to distinguish the precise roles played by these soluble and insoluble organic phases.

Based on the above discussion, it is presently clear that proteins determine the mineral polymorph and, possibly, also the nucleation and shape of crystals, but it is not at all clear how they determine other aspects, such as crystal orientation and growth rate. Particularly intriguing is the production of conspicuous intercrystalline organic membranes. Here I will review the existing knowledge on the mechanisms of microstructure fabrication, i.e., those which help us to understand how microstructures acquire their incredible degree of sophistication. These properties are essential with regards to the biomechanical properties. The unveiling of the fabricational strategies is also essential for future biomimetic studies, since, in theory, these strategies could be used as inspiration for the production of highly functional synthetic materials.

\section{MECHANISMS OF MICROSTRUCTURE ORGANIZATION}

\section{Crystal Competition}

This process happens in aggregates of elongated crystals growing with a well-defined growth front. The crystals within the aggregate with their fastest growth (crystal) axes subperpendicular or perpendicular to the growth front will intercept those growing obliquely and will outcompete them (crystal selection). In this way, the fastest growth axes of the survivors will be progressively co-oriented in the growth direction of the aggregate. Crystal selection may account for 

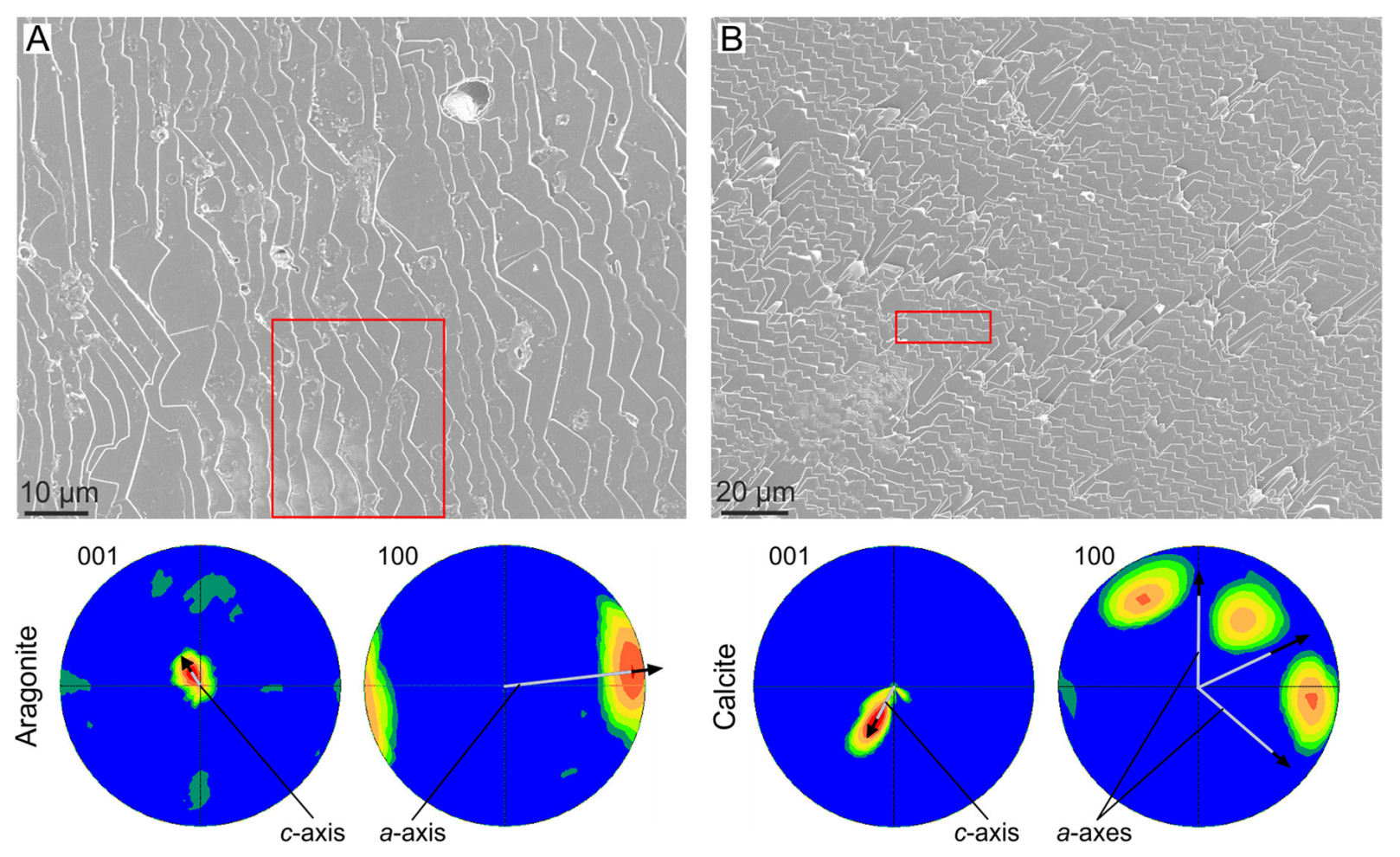

FIGURE 4 | Crystal coorientation in foliated materials. (A) Foliated aragonite of the monoplacophoran Rokopella euglypta. (B) Foliated calcite of the bivalve Anomia ephippium. In both cases, the EBSD pole figures of the areas framed in red [the position of the area in (B) is approximate] are shown below. For both materials, the small scatter of the pole figure maxima indicate a good co-orientation of both the $c$ - (001 pole figures) and a-axes (100 pole figures). The average orientations of the crystallographic axes is indicated. Their inclinations with respect to the plane of the image are inversely proportional to their lengths, e.g., for aragonite, the $c$-axis is at a high angle to the image plane, whereas the a-axis is at a low angle (close to the horizontal).

cases in which crystals are elongated (fibers, prisms) and grow with their long axis perpendicular or at a high angle to the common growth front. As a result, only the axis of elongation (usually, though not always, the $c$-axes in biocalcite and the $a$ - or $c$-axes in bioaragonite) becomes co-oriented and a fiber texture finally results.

Crystal selection by competition has been postulated in the columnar prismatic calcite of pinnoideans and pterioideans (Ubukata, 1994), the columnar prismatic aragonite of unionids (Ubukata, 1994; Checa and Rodríguez-Navarro, 2001), the calcitic prismatic layers of the Argonauta shell (Stevens et al., 2017), the foliated calcite of bivalves (Checa et al., 2007), the foliated aragonite of monoplacophorans (Checa et al., 2009a, b) and the nacre of bivalves (Checa et al., 2006). From the above-mentioned cases of prismatic materials referred to in the literature to orient by competition, the columnar prismatic layers of pinnoideans, pterioideans and unionoids can be excluded because the columnar prismatic units are surrounded by thick organic membranes, which determine the growth dynamics of the aggregate (see below). Additionally, no evidence that crystal co-orientation progresses with time has been provided. Presently, the only well-documented case is that of the calcitic prismatic layer of the shell secreted by the female Argonauta (which is not homologous to the shells of other molluscs). Stevens et al. (2017) showed how crystal co-orientation increases during growth of the layer, which is fully consistent with selection by competition. The non-columnar calcitic prismatic layers of euheterodont bivalves also display fiber textures (Harper and Checa, 2017). Since they do not bear intermediate organic membranes and crystals elongate in the growth direction, this crystallographic pattern is quite possibly acquired also by crystal competition.

Crystal co-orientation will also be attained when lath-like crystals are arranged into 2D lamellae. Provided that individual crystals have consistent crystallographies, competition will give rise to a sheet texture. This is the case of the foliated aragonite of the monoplacophorans (Checa et al., 2009b) and of the foliated calcite of the Ostreoidea and Pectinida (Checa et al., 2007), where foliae are composed of evenly oriented crystals, with all axes cooriented (Figure 4). The case of progressive co-orientation of bivalve nacre implied by Checa et al. (2006) is doubtful, because it only applies when nacre tablets elongate along the $b$-axis, which is not always the case.

Crystal interaction in molluscan microstructures is particularly intense because they are compact materials, with a negligible amount of porosity. The only exception known is that of chalk (Figure 1C), a particularly soft and porous material (up to $80 \%$; Korringa, 1951) fabricated by oysters. It is composed of an apparently disorganized array of laths. In coincidence, it seemingly displays a high degree of crystallographic disorder (Checa et al., 2018). Although more information is needed on the 

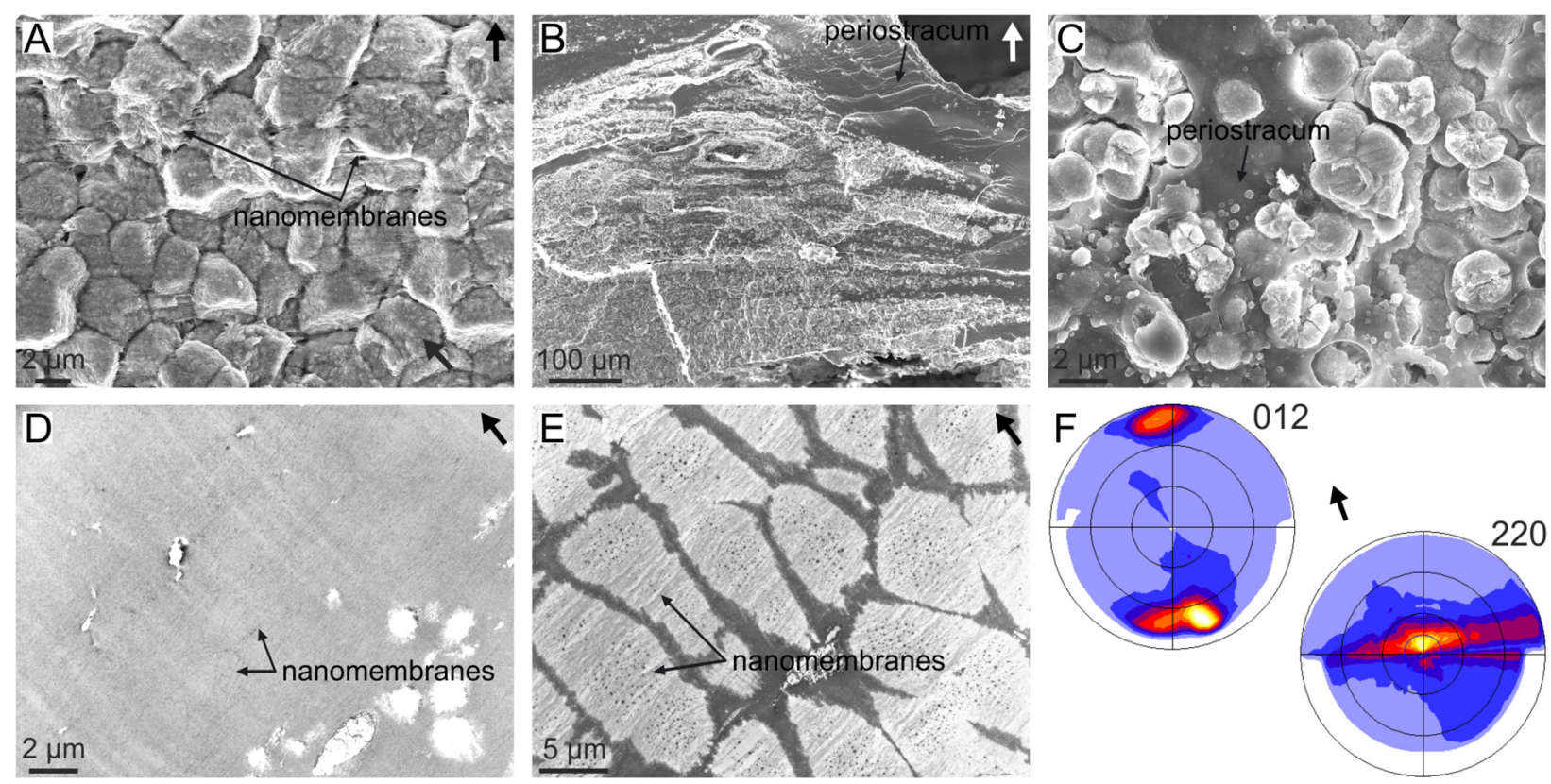

FIGURE 5 | Organization of the granular prismatic microstructure of the outer shell layer of the bivalve Entodesma navicula. (A) Vertical fracture of the granular layer, showing the aspect of the granular crystals. The horizontal organic nanomembranes of the translucent periostracal layer are also visible. (B) General view of the outer granular prismatic layer. The granules are distributed into bands interbedded within the periostracum (dark organic material). (C) Prismatic granules growing within the periostracum (dark organic material). (D) TEM view of the non-calcified periostracum, showing its nanolaminated structure. (E) Decalcified granular prisms. The periostracal nanomembranes incorporated by the crystals are evident. (F) XRD pole figures obtained on a fracture similar to that in (A). The 012 pole figure indicates that the $c$-axis is perpendicular to the outer shell surface (or the nanomembranes) and the 220 pole figure implies that the $a$-and $b$-axes are rotated around c. This is called a fiber texture, with the c-axis as fiber axis. Arrows point to the outer shell surface. (E,F) Modified from Harper et al. (2009).

chalk, it provides an example of how important space restriction is for an effective organization based on crystal competition.

\section{Orientation by Interaction With Organic Matrices}

The presence of organic sheets may provide sites for oriented nucleation. In particular, the interaction of charged ions on the surface of the organic sheets (i.e., aspartic acid-rich proteins) favors the oriented nucleation of aragonite or calcite with the positively charged calcium layers (i.e., the $\{001\}$ basal planes, which are perpendicular to the crystallographic $c$-axis) parallel to the sheets (Addadi et al., 1987). This effect is undoubtedly due to the activity of proteins, but it should be differentiated from other instances because it happens at extracrystalline level and affects crystal aggregates instead of single crystals, and the protein fraction is organized onto a chitin or chitin + protein scaffold instead of proteins being dispersed within the extrapallial fluid.

Cases in which short crystals develop a fiber texture cannot be due to crystal competition, because a sine qua non-condition is that crystals elongate in the fastest growth direction with time. This is the case of the granular (i.e., very short) prismatic units of the outer shell layer of the anomalodesmata bivalve Entodesma (Harper et al., 2009) (Figure 5A). These granules grow within the so-called translucent layer of the periostracum, which is a non-tanned periostracal layer composed of parallel nanolaminae (Figures 5A-D). During growth, the granules absorb the nanolaminae, which is revealed upon the decalcification of the granular units (Figure 5E). Despite their morphology, the granular units are oriented with their $c$-axes perpendicular to the periostracum (i.e., the outer shell surface) (Figure 5F). This orientation is most probably determined during the nucleation stage by the interaction of the negatively charged protein sheets making up the nanolaminae with the positively charged calcium planes of the aragonite structure (which are perpendicular to the crystallographic $c$-axis). The same applies to mineralized spikes and plaques that form intraperiostracally in many other anomalodesmatans, and which always grow with their $c$-axes perpendicular to the periostracum surface (Checa and Harper, 2010).

The anvil-type calcitic fibrous outer shell layer of Mytilus (Figures 1D, 6A) has a sharp sheet texture (Figure 6B), which is unexpected since competition would only lead to a fiber texture, with the $c$-axis of calcite fibers as fiber axis. The mineralization compartment of this microstructure is covered by a proteinaceous layer called the surface membrane (Figures 6C-E). This membrane has a fibrous aspect under the scanning electron microscope (SEM) (Figure 6C), and appears nanolaminated internally under TEM (Checa et al., 2014a) (Figure 6D). How fibers inevitably have one of their $\{10 \overline{1} 4\}$ rhombohedral surfaces strictly parallel to and in contact with the surface membrane can also be observed (Figure 6E). Experiments of precipitation of synthetic calcite both on the unaltered membranes and after decalcification demonstrate that: 

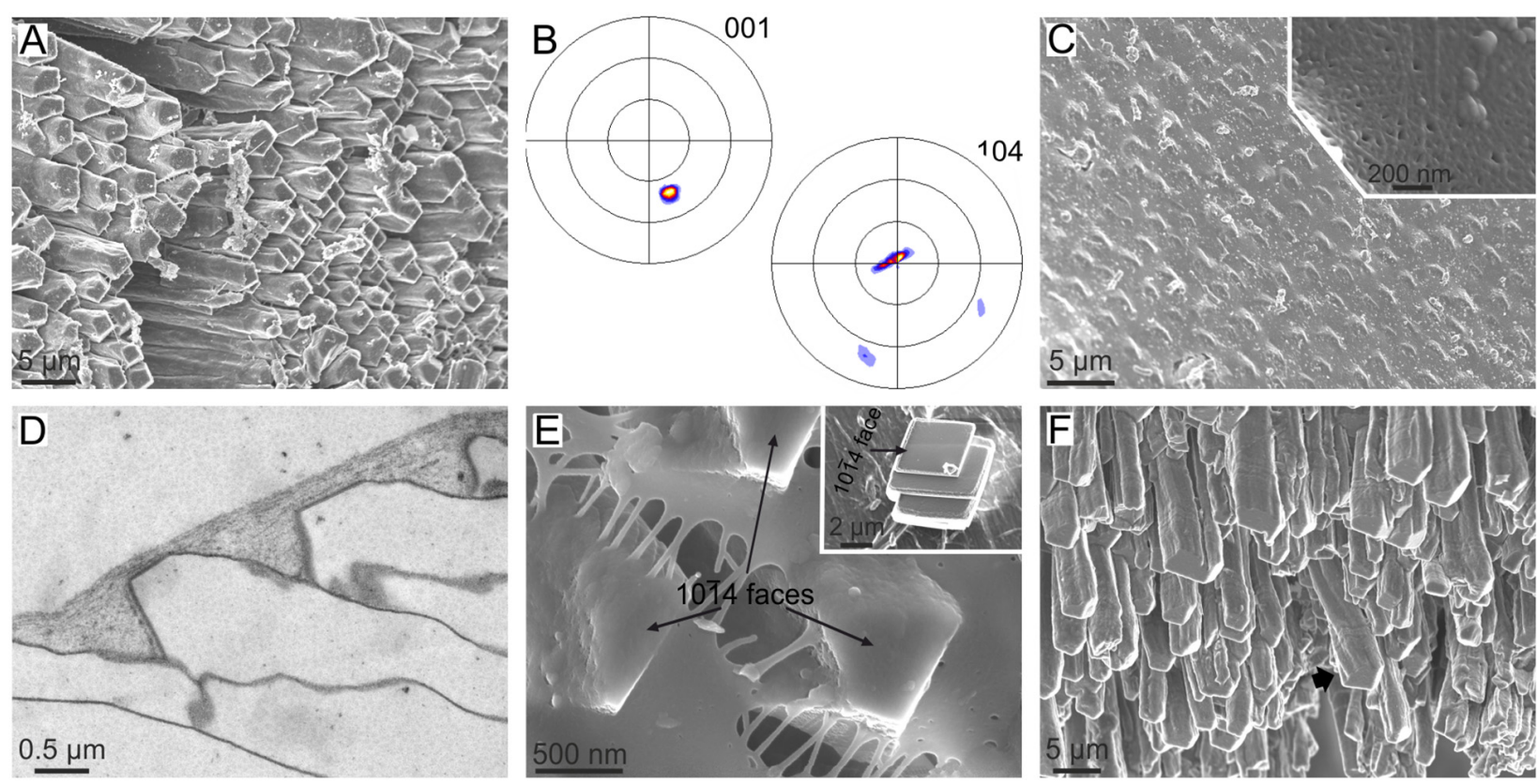

FIGURE 6 | The calcitic fibrous layer of mytilid bivalves and its relationship with the surface membrane. (A-E) Mytilus galloprovincialis. (A) Aspect of the growth surface of the fibrous layer. Note the even orientation of the $10 \overline{1} 4$ faces (slightly darker in the image). (B) XRD pole figures of the fibrous layer seen from the growth surface. The orientation is similar to that in (A), but the pole figures are rotated clockwise by ca. $70^{\circ}$. The pole figures reveal a sheet texture. (C) Outer aspect of the membrane, with the calcitic fibers slightly protruding from below the membrane. Inset, fibrous texture of the surface membrane. (D) TEM section along the axis of fibers and the surface membrane. The nanolaminated aspect of the latter is evident. (E) Detail of the tips of fibers. Their $10 \overline{1} 4$ faces are perfectly cooriented, and one of them (the one looking toward the observer) is strictly parallel to the surface membrane. Inset, synthetic calcite crystal grown on the underside of an isolated surface membrane. It grows on a $10 \overline{1} 4$ face. (F) Growth ends of the fibers of Bathymodiolus azoricus. Note the bending and twisting (arrow) fibers. (A-D,F) Modified from Checa et al. (2014a).

(1) the surface membrane is transparent to ions or $\mathrm{CaCO}_{3}$ nanoaggregates, and (2) synthetic calcite crystals nucleate on the underside of the membrane on their $\{10 \overline{1} 4\}$ faces (Figure $6 \mathrm{E}$, inset), i.e., this membrane has an affinity for such crystallographic faces. Additionally, the calcite fibers of Mytilus have been shown to be able to twist and bend (Figure 6F). Checa et al. (2014a) hypothesized that during growth, every fiber twists and/or bends until one of its rhombohedral faces becomes parallel to the surface membrane. From here on, this face becomes "locked" to the surface membrane. In this way, the aggregate of fibers finally acquires a sheet texture by interaction with the surface membrane.

\section{Self-Organization Processes \\ The Interlamellar Membranes of Nacre}

Nacre is the most iconic molluscan microstructure and is characterized by having a brickwall stacking mode in which the bricks are aragonitic tablets (Figure 1J) and the mortar is horizontal, interlamellar membranes (Figures 7A-D) and vertical, intertabular membranes. While the intertabular membranes have no defined structure and seemingly consist only of organic material trapped between platelets, the interlamellar membranes have a felt-like structure (Figures 7C,E), consisting of fibrils of a chitin (most probably $\beta$-chitin) + protein complex, surrounded by proteins (Levi-Kalisman et al., 2001; OsunaMascaró et al., 2015). In excellent TEM sections across the shell and mantle of the bivalve $P$. radiata, Bevelander and Nakahara (1969) and Nakahara (1991) showed how tablets in a given lamella are ineluctably covered by an interlamellar membrane, which is at a very short distance to the mantle cell microvilli. At its distal end, every new interlamellar membrane is at a distance of ca. $90 \mathrm{~nm}$ from the preceding interlamellar membrane (Cartwright and Checa, 2007; Figure 7D). Moving back from the growth rim, this distance increases progressively to the usual platelet thickness of mature nacre $(300-500 \mathrm{~nm})$. Around this distance (estimated at $\sim 20 \mu \mathrm{m}$ in Cartwright and Checa, 2007), nacre crystals begin to grow within the interlamellar spaces (Figure 7D). This process is sketched in Figure 7F. The cells of the mantle surface are never in contact with the forming nacre platelets because there is always an interlamellar membrane inbetween. The same applies to gastropods in which the whole nacre biomineralization compartment is isolated by a relatively thick $(\sim 100 \mathrm{~nm})$ surface membrane (Figures 7A,B), from which the successive interlamellar membranes detach. Nacre platelets later begin to grow within the newly created interlamellar spaces (see sketch in Figure 7G). In any case, it is necessary for the interlamellar membranes to be transparent to the aggregation units, whether ions or nanoparticles.

How the animal is able to precisely control the distribution and distances between interlamellar membranes at such a nanometric scale is difficult to explain, unless by a physical process operating at a molecular or nanoparticle level. If we make 

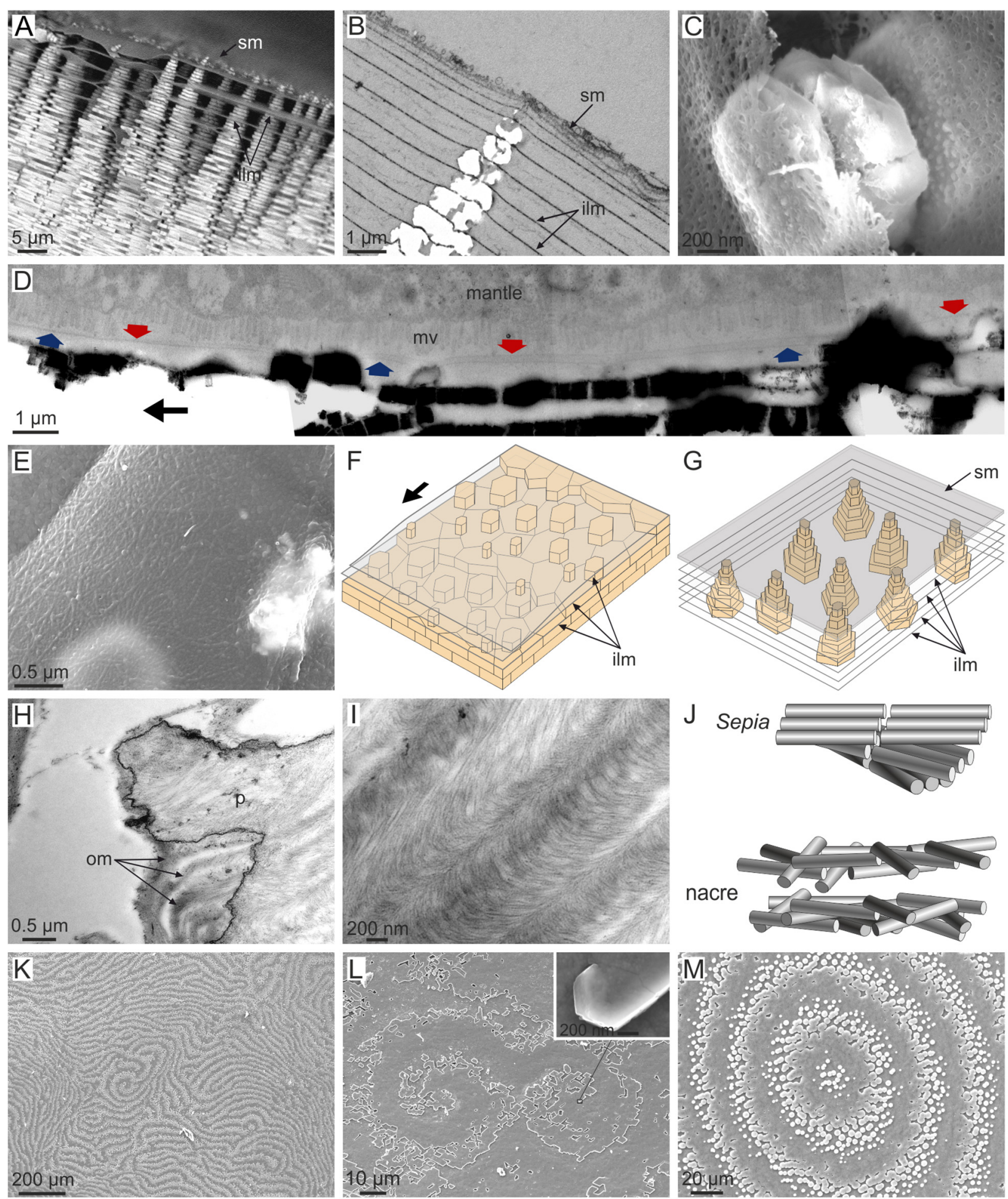

FIGURE 7 | Distribution and structure of interlamellar membranes in gastropod (A-C,G) and bivalve (D-F,K-M) nacre, and comparison to the organic membranes in Sepia (H-J). (A) Jujubinus pseudogravinae. Typical tower-like arrangement of gastropod nacre, with interlamellar membranes subtending between tablets. The tips of the towers are embedded within the surface membrane. (B) Monodonta labio. TEM section through a tower of tablets and intervening interlamellar membranes. The latter predates the former. (C) Steromphala pennanti. Growing nacre tablets between interlamellar membranes. Note the fibrous nature of the membranes.

(D) Pinctada fucata. Section through the mantle and nacre (composite TEM micrograph). The tracings of two interlamellar membranes covering the two most recent lamellae are indicated with arrows in different colors. The membranes become progressively closer in the growth direction (indicated by the black arrow). 
FIGURE 7 | Continued

(E) Anodonta cygnea. Interlamellar membrane displaying a fibrous aspect. (F) Model for the growth of nacre in bivalves. A fresh membrane is progressively secreted in the growth direction (arrow) at a very short distance from the previous membrane, and later separates to the usual tablet thickness. Tablets later initiate and grow within the newly created interlamellar spaces. (G) Model for the growth of nacre in gastropods. The interlamellar membranes detach from the surface membrane and tablets grow within the created interlamellar spaces. (H) Cephalopod Sepia officinalis. TEM view of the interior of a decalcified chamber showing the arrangement of horizontal organic membranes. These are continuous from the interior of the pillar to the empty space of the chamber. (I) Sepia officinalis. Detail of such membranes showing the arcuate arrangement of chitin fibrils. (J) Models for the 3D arrangement of fibrils in the organic membranes of Sepia and in the interlamellar membranes of nacre. (K) Pteria avicula. Digitiform arrangement of the growth fronts of nacre lamellae. (L) Pteria hirundo. Nacre growth fronts forming a double spiral. The inset shows a spirally growing nacre tablet at the very origin of the right spiral. (M) Pteria avicula. Target pattern formed by the growth fronts of nacre. ilm, interlamellar membrane; mv, microvilli; om, organic membrane; p, pillar; sm, surface membrane. (B,E) Modified from Cartwright et al. (2009); (D,K,M) modified from Cartwright and Checa (2007); (H,I) modified from Checa et al. (2015).

an abstraction of nacre platelets (which come later, Nakahara, 1991; Figures 7F,G), we are left with a series of parallel layers (the interlamellar membranes), each having a fibrous nature. In particular, such a situation is obtained during the formation of liquid crystals. Liquid crystals are a state of matter which have properties of both liquids (e.g., fluidity) and crystals (e.g., optical or magnetic properties) (e.g., Andrienko, 2018). Liquid crystals are made of polar fibers or molecules, which align due to electrostatic interactions. There are many different types of liquid-crystal phases. Of the several possibilities, a common final configuration is the so-called cholesteric or chiral-nematic phase, in which fibers or molecules are arranged in planes, with the fibers in each plane being parallel to each other and slightly rotated with respect to those of the preceding plane. After a certain distance ("pitch") the orientation of the fibers is exactly the same. When a series of planes with a cholesteric configuration are sectioned, it provides a typical arcuate pattern with a regular repetition.

Liquid-crystal self-organization has been applied to explain the plywood structures of many fibrous biocomposites ranging from plant cell walls to bone, including invertebrate skeletons (Neville, 1993). Possibly the best-known example is that of the arthropod exoskeleton, which is made of $\alpha$-chitin fibers (Bouligand, 1972). In molluscs, patterns typical of cholesteric phases have been recognized in the periostracum of some gastropods (Neville, 1993), the squid pen (Levi-Kalisman et al., 2001), and the chambers of Sepia (Checa et al., 2015; Figures $\mathbf{7 H}, \mathbf{I}$ ). The material composing the chamber of Sepia is, interestingly, homologous to the cephalopod nacre.

Compared to a typical cholesteric phase, in which fibers in a layer are oriented in parallel, the interlamellar membranes appear disorganized (Figure 7J). This may happen because either they have not had sufficient time to assemble in parallel or the observed length of the fibers (tens of microns; Figures 7C,E) hinders a parallel arrangement.

Another important difference is that in liquid crystals formed in vitro all layers develop at once from a suspension. Regarding nacre, we need to consider the case of a layer-by-layer liquid crystal, in which every new layer is added during growth at the same time as the preexisting layers extend at their edges.

The liquid-crystal hypothesis for the formation of the interlamellar membranes of nacre is an easy way to understand how such a complex structure is secreted via a simple physical mechanism. This is particularly relevant in the case of gastropod nacre in which the nacre compartment is protected by the surface organic membrane (Figures $\mathbf{7 A , B}, \mathbf{G}$ ), such that the mantle is never in direct contact with the forming interlamellar membranes (Checa et al., 2009a). In these circumstances, an explanation based on self-organization by liquid crystallization seems the only available resource.

Similar to crystals, defects are also common in liquid crystals. Screw and edge dislocations are typically developed in cholesteric liquid crystals, with layers of crystallites or molecules being analogous to atomic or molecular terraces in crystals. Comparable features are also found in the interlamellar membranes of bivalve nacre (Figure 7K). Screw dislocations manifest themselves as the spiral patterns typically observed in the nacre of bivalves (Figure 7L) and gastropods, which are resolved at their very axis in a single tablet with screw growth (Figure 7L, inset). Spiral and target patterns have been modeled theoretically by assuming that the nacre formation system is an excitable medium, which conforms to a layer-bylayer liquid crystal (Cartwright et al., 2009). Bivalve nacre forms target patterns (Figure $7 \mathbf{M}$ ), which are comparable to growth hillocks produced during the formation of new atom planes in a growing crystal. That these patterns belonged to the interlamellar membranes and were later mineralized during tablet formation is manifested by the fact that it affected not just one (which would be the case if they were defects arising in single tablets) but hundreds of tablets, i.e., the whole growth front of the interlamellar membrane.

Bevelander and Nakahara (1969) and Nakahara (1991) demonstrated that nacre tablets begin to grow within the spaces between the preformed interlamellar membranes (Figures 7A$\mathbf{D}, \mathbf{F}, \mathbf{G})$. It is now clear that tablets do not nucleate onto the interlamellar membranes, but rather find their way through them through tiny holes (>100 $\mathrm{nm}$ ), which result during initial (as in gastropods) or advanced (as in bivalves) growth of tablets (Checa et al., 2011). In this way, parental and filial tablets connect across the so-called mineral bridges (initially defined by Schäffer et al., 1997).

Although there is no hitherto evidence, it is likely that nanolayered organic membranes of the kind described in the preceding section (the periostracum of anomalodesmatan bivalves and the surface membrane carpeting the calcitic fibrous layer of mytilids internally) are also self-organized.

\section{Organic Envelopes Around Columnar Prismatic Units}

Bayerlein et al. (2014) presented a physical explanation for the external calcitic prismatic layers of the pen shell $P$. nobilis, based on synchrotron X-ray tomography. These prismatic layers 
belong to a family of materials found in many bivalves of the order Pteriomorphia (including pen-shells, pearl oysters, oysters, saddle oysters, and some scallops). They are strictly termed calcitic columnar prismatic microstructures and consist of prismatic units of calcite with regular polygonal cross-sectional outlines surrounded by relatively thick $(0.5-3 \mu \mathrm{m})$ organic membranes, which elongate and grow perpendicular to the shell surfaces (Figures 1E, 8A). Bayerlein et al. (2014) presented reliable evidence that the columnar prismatic units evolve in such a way that those units with larger cross-sectional area and/or a number of sides greater than six grow at the expense of the units with smaller area and/or a number of sides lower than six (Figure 8A). The latter will shrink with time, eventually disappearing. They interpreted this pattern on the basis of the normal grain growth theory (von Neumann, 1952; Mullins, 1956) which predicts exactly the same evolution in an aggregate of crystals (mainly metals) subjected to high temperatures. They also remarked on how the sides of the polygons form triple junctions at $120^{\circ}$ (Figures 8A-D), which is the condition for surface tension to remain constant throughout the aggregate (Plateau's law). Alternatively, Checa et al. (2016a) objected to such an explanation because in biogenic prismatic calcite regular polygonal outlines are only found in the presence of organic membranes, whereas in their absence, boundaries are complex pseudodendritic. In addition, in many instances, the prismatic units are polycrystalline (Figures $\mathbf{8 B}, \mathbf{C}$ ), cavities can exist in the absence of mineral infilling and the outlines of the prismatic units change with the growth or disappearance of organic walls (Figures 8D,E). This and additional evidence led these authors to propose that the evolutionary dynamics observed by Bayerlein et al. (2014), instead of being due to the crystals, can be attributed to the organic envelopes of the prisms. Normal grain growth is only one of a series of phenomena to which the von NeumannMullins topological law can be applied, including foams (on which the von Neumann-Mullins law was originally developed) and emulsions. It is hard to conceive which kind of physical process a system composed of the polymerized membranes and the mineral grains may correspond to, but the picture becomes much clearer if we think about the precursors of the two materials: (1) the fluid, gel-like precursor of the membranes, and (2) the liquid precursor of the mineral phase. The latter is the so called polymer-induced liquid precursor (PILP), and there is evidence that it is generated by acidic biopolymers in synthetic systems (Gower, 2008; Schenk et al., 2012). This PILP phase is hypothesized to be present during biomineral formation as well. This two-liquid system would constitute an emulsion (i.e., a dispersion of minute droplets of one liquid into another in which it is not soluble or miscible); the fluid precursor of the organic web would constitute the continuous phase and the PILP, the discontinuous phase (Checa et al., 2005, 2016a) (Figure 8F). Accordingly, the growth of the calcitic columnar prismatic layers is a self-organized process, in which the membranes control the pattern and the mineral enclosed within the organic membranes passively adjusts to the dynamics dictated by the latter.

Exactly the same growth dynamics of organic membranes has been observed in the aragonitic columnar prismatic layers of the freshwater bivalves of the order Unionida (Figure 8D). This material is made of organic cavities, which are, in turn, filled with fibrous aragonite, and to which the emulsion hypothesis of self-organization can also be applied confidently.

Similar prisms are produced by the only extant representative of the bivalve order Trigoniida (closely allied to Unionida), Neotrigonia. Unlike in the Unionida, the prisms of Neotrigonia are all the same size and retain a hexagonal outline (Checa et al., 2014b) (Figures 1H, 8G). As a consequence, they do not compete during growth and the same number of units which initiated at the outer side of the layer reach the internal side. This is achieved by the animal precisely placing the initial prism nuclei equidistant from each other (see below).

\section{Direct Cellular Activity}

As discussed above, the thickness of the extrapallial space in molluscs is negligible or, in other words, the microvilli of the mantle cells are virtually in contact with the forming shell (Figure 3). According to Bevelander and Nakahara (1969), Nakahara and Bevelander (1971) and Nakahara (1991), this is also the case of the pearl oyster Pinctada. Directly in contact with the growth surface of the columnar prismatic layers, independent of whether they are calcitic or aragonitic, there are mantle cells with diameters of $5-10 \mu \mathrm{m}$, which secrete a network of membranes $0.5-3 \mu \mathrm{m}$ wide, and mineral domains of up to $120 \mu \mathrm{m}$. We are faced with two possibilities: (1) the cells secrete mineral and organic components in an undifferentiated manner and these diffuse across the extrapallial space to the corresponding positions in either the membranes or the mineral domains or (2) the cells selectively add new organic components to the organic membranes and mineral components to the mineral units to extend the pattern. In case (1) the molecules or ions have to travel laterally for distances of microns to tens of $\mu \mathrm{m}$ to their corresponding positions, without any particular driving mechanism (e.g., electrochemical) being known. In the much more likely case (2), every mantle cell (whose diameters are far greater than the thicknesses of the membranes) must be secreting both organic and inorganic materials, depending on exactly which components it is in contact with. Since shell secretion is a periodical process, and the mantle is able to move relative to the shell surface, the mantle-shell contact is not permanent (Figure 8F, left panel). This implies that, every time a secretion period is about to start, the mantle cells must first be able to recognize the exact configuration of the organic-mineral pattern which they are in contact with (Figure $\mathbf{8 F}$, right panel). In summary, contact recognition followed by secretion must take place. It should also be emphasized that these processes must occur at subcellular level (Checa et al., 2016a), which is so far unknown in biomineralization. This implies that cells are actively controlling the deposition process, although they do not influence the pattern of the organic network, which is only guided by physical laws (see above).

As commented on above, the regular distribution of the prisms of the bivalve Neotrigonia causes them to have even dimensions and regular pseudohexagonal crossed sectional outlines. In this way, competition is totally inhibited (Figure 8G). Their deposition already begins within the periostracal groove (Figures 3B,C) with mineral bosses ( $\sim \mu \mathrm{m}$ in diameter) 

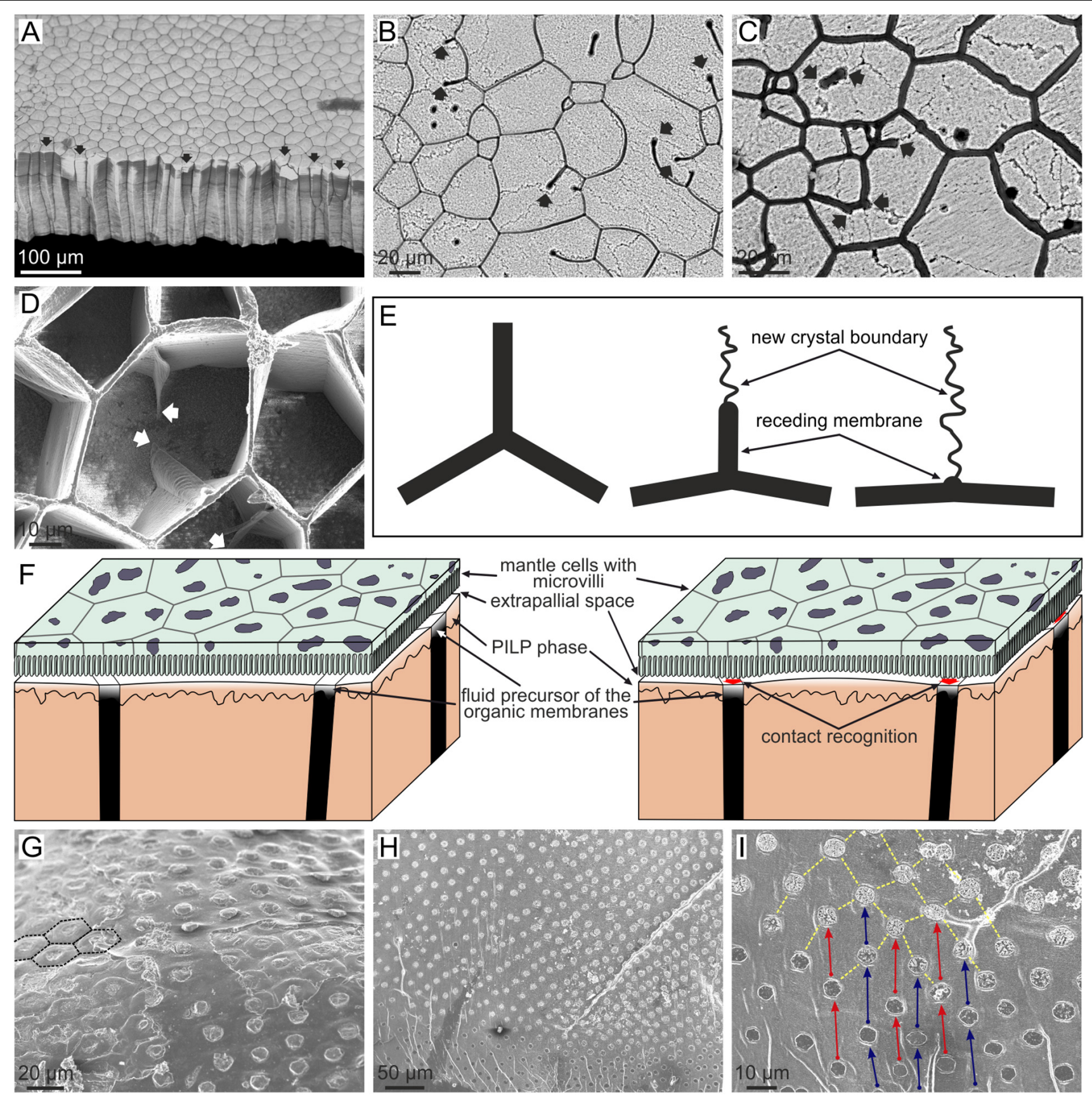

FIGURE 8 | Evolution of columnar prismatic layers in bivalves. (A) Fracture of the calcitic layer of Pinctada margaritifera. Those prisms with less than six sides (arrowed) wedge out and disappear during growth (bottom of the image). The contrary is true for prisms with six or more than six sides. (B,C) Growth surface of the prismatic layers of Pinctada margaritifera. The mineral columnar units are polycrystalline; the boundaries between crystals are visible under slight etching. Receding membranes are indicated with arrows. Note that they leave crystal boundaries behind. (D) Semi decalcified aragonitic layer of Anodonta cygnea seen from the growth surface. The arrows point to receding membrane. Note how the triple points formed by membranes at the depressed mineral surface progressively revert to flat membranes. (E) Mechanism of recession of a membrane and resulting change in the morphology of the triple meeting point. The receding membrane, which originally separated two crystals, leaves a crystal boundary behind. (F) Model for the formation of columnar prismatic materials. The left sketch corresponds to the non-secretion period. When secretion is about to resume (right sketch), the cells recognize the positions of the organic membranes in order to secrete both the organic and mineral phases separately. The emulsion is formed between the fluid precursors of the organic and mineral phases. (G) Outer shell surface of Neotrigonia lamarckii. The prismatic units have a regular distribution and pseudo-hexagonal contours (some of them have been outlined with broken lines). (H,I) Free periostracum of Neotrigonia gemma. The bosses, which constitute the nuclei of the aragonitic prisms, have a regular grid-like distribution. In the close up view (I) corresponding bosses are joined by arrows, which also indicate the growth direction. (B,E) Modified from Checa et al. (2016a). 
distributed into radial rows spaced 20-30 $\mu \mathrm{m}$ apart. The bosses in every row are spaced at approximately the same distance, and offset with respect to bosses in adjacent rows (Figures $\mathbf{8 H}, \mathbf{I}$ ). In this way, they form a regular grid on the outer periostracal and shell surface. This arrangement implies that there must be specific positions of the outer mantle epithelium where cells or, more strictly, subcellular areas, are specialized in the production of new bosses and which are evenly spaced along a comarginal direction (Checa et al., 2014b). Once a new boss has been produced, the subcellular site enters a refractory period until it becomes activated again for the production of a new boss (Figure 8I). In this way, the bosses also become regularly spaced in the longitudinal direction. For the grid-like pattern to arise, production sites should become activated alternatively in adjacent radial rows.

Possibly, the most 'exotic' microstructure (in the sense that it looks anything but a crystalline aggregate) is the so-called aragonitic helical fibrous microstructure (Bé et al., 1972), which is fabricated by a small group of planktonic gastropods, the Cavolinioidea. It consists of very thin ( $\sim 300 \mathrm{~nm}$ thick) aragonite fibers which coil helically in several turns (up to 3.5 in some instances, e.g., Cuvierina; Figure 9A) along an axis perpendicular to the shell's surface. All helices within the material have their coiling axes parallel, having exactly the same leading angle and amplitude, and are in phase, so that, at a given depth within the shell, all fibers are co-oriented. Only their coiling axes are mutually displaced. Accordingly, the fibers permanently intersect each other, which causes permanent changes in their cross-sectional outlines, although all of them manage to survive the constant process of interlocking (Figures 9B,C). Each fiber consists of a myriad of $\{110\}$ twinned aragonite crystals, with their common $c$-axis parallel to the coiling axis (Willinger et al., 2016). Accordingly, it is clear that the helical trajectories are not guided by crystal growth. On the internal (growth) surface of the shell, the outlines of the fibers appear very elongated in the growth direction, and, invariably, there is a minute bulge positioned at the anteriormost end of every fiber (Figures 9D,E), which elevates between 30 and $90 \mathrm{~nm}$ above the internal shell surface, depending on the species (Checa et al., 2016b) (Figure 9F). This feature has never been observed in the growth surface of any other molluscan microstructure. The elevated bulge is the means by which a given fiber avoids extinction, since, in being elevated above the growth surface, it cannot be overgrown by neighboring fibers. However, at the same time, the bulges provide a clue as to the fabrication of helical fibers. Despite their minute sizes and elevations, they can be perceived (recognized) by the mantle cells, which would acquire the necessary positional information to continue the secretion of the corresponding fiber (Figure 9G).

In order for the tips to move with time along helical trajectories, the mantle cells must be able to propagate their secretion onto the 2D mantle surface along circular trajectories (by e.g., reaction-diffusion processes of morphogens) (Figure 9H). The increase in shell thickness with time provides the necessary translation along the coiling axis (perpendicular to the shell surface) to generate the helical movement. In summary, each fiber would be produced à la carte' by the mantle cells. In more detail, taking into account that bulges are much smaller than mantle cells, their detection, secretion and translation has to take place within areas much smaller than those typical of single cells.

\section{PHYSICAL VS. BIOLOGICAL INFLUENCES ON INDIVIDUAL MICROSTRUCTURES}

According to the above discussion, some microstructures are strongly influenced by physical processes (crystal competition and self-organization), whereas others are mainly influenced by biological processes, including the simple activity of proteins on the crystal shape. Others result from a combination of both types of influences. It is then possible to plot the known positions of those microstructures in the fabrication process on a bivariate diagram, with one axis corresponding to physical determinants and the other to the biological determinants, such as that of Figure 10.

Some microstructures (e.g., foliated) acquire their degree of organization according to simple crystal growth (i.e., physical) processes (crystal selection by competition). This is the case of the non-columnar prismatic microstructures, which are the closest analogs to non-biogenic calcite (e.g., the cephalopod Argonauta and the bivalve Chama). Foliated materials, also organize basically by similar processes, although the shapes of crystals are largely influenced by soluble proteins. Microstructures which organize by interaction with organic matrices (e.g., fibrous calcitic of mytilids) must be considered as a separate strategy. By assuming that these organic matrices are formed by selforganization, they can be placed in the top half of the diagram. A particular category is constituted by those having conspicuous separate organic phases, which organize into frameworks according to self-organization processes. This is the case of nacre (self-organized by liquid crystallization) and of the prismatic columnar microstructures (organic-PILP emulsion). There is nevertheless a distinction between them, because the fabrication of the prismatic columnar microstructures also demands direct cellular activity in the form of subcellular recognition and secretion, therefore being of a mixed physical/biological nature. The columnar prismatic layers of Neotrigonia are particularly appealing, since the mantle cells also actively determine the regular disposition of the prismatic units, which hinders their further evolution. The extreme case of biological control described so far is that of the aragonitic helical fibrous microstructure, in which the whole pattern is determined by cellular (subcellular, in strict terms) activity.

This kind of classification allows us to make some adaptive and evolutionary inferences. From this suite of microstructures, the two based on self-organization are particularly suited for biomechanical purposes. Nacre is known for being the strongest of all molluscan microstructures, whereas the columnar prismatic materials are exceptional in flexibility, due to the high elasticity of the constituent organic membranes. From an evolutionary perspective, microstructures based on physical laws (either crystal growth or self-organization) seem particularly prone to appear repeatedly during evolution. Foliated 

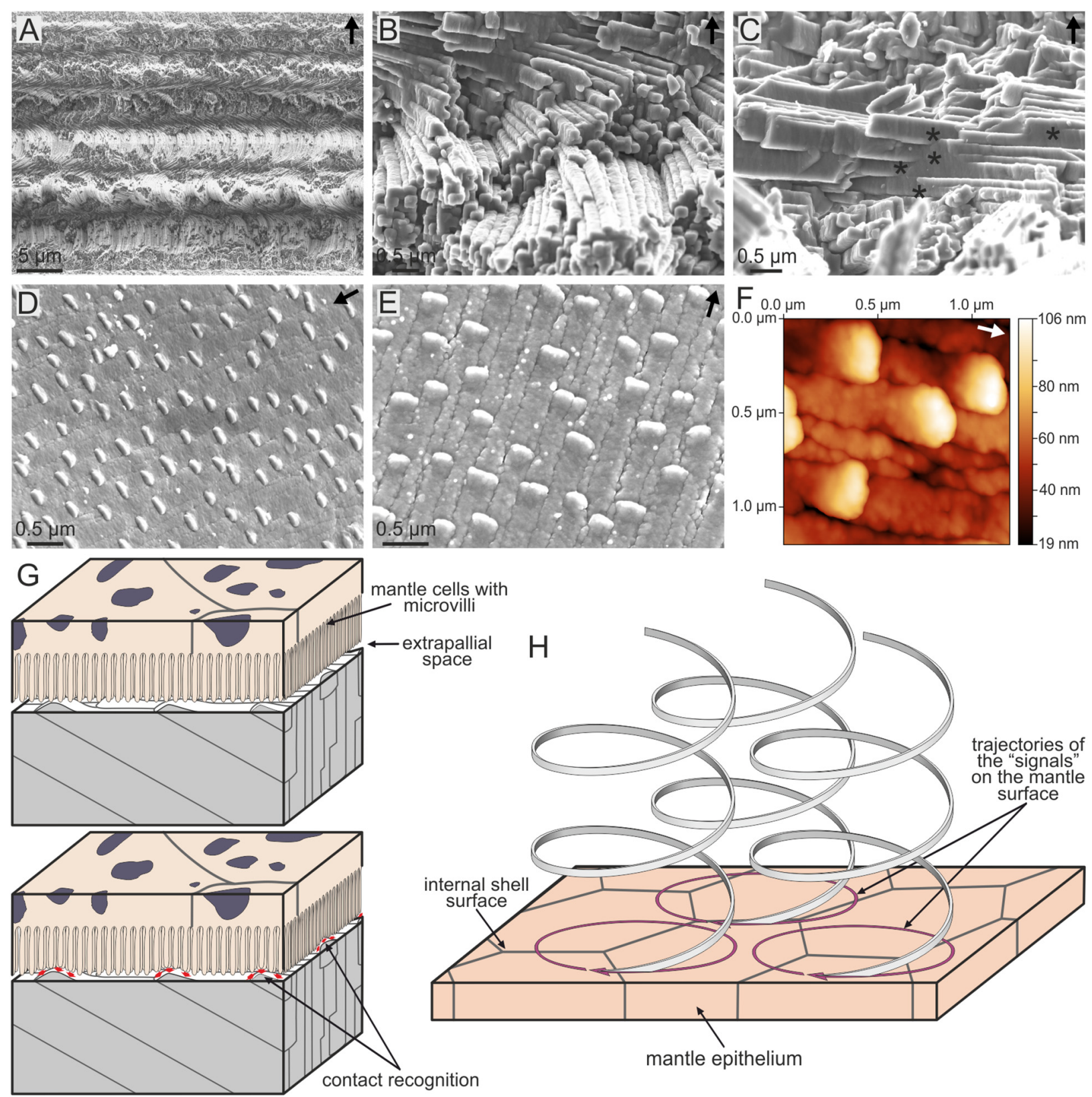

$\mathrm{H}$
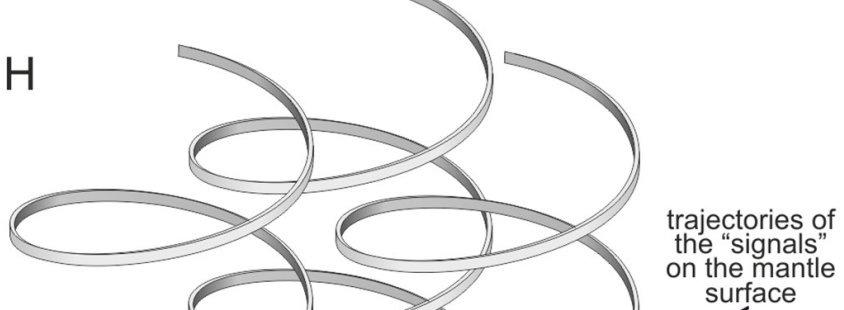

on the mantle

FIGURE 9 | The aragonitic helical fibrous microstructure of cavolinioidean gastropods. (A) Fracture through the shell of Cuvierina columnella. The helices coil for more than three complete turns. (B) Detail of the microstructure of Clio pyramidata. Note the close packing and the high degree of interpenetration of fibers.

(C) Interpenetration of fibers (asterisks) in Creseis acicula. (D) Oblique view of the internal shell surface of Cuvierina columnella, showing the elevated anteriormost tips of fibers. (E) Plan view of the internal shell surface of Creseis clava. As in (D), each fiber has an elevated growth tip. (F) Atomic force microscopy view (topography image) of the internal shell surface of Cuvierina columnella. The tips of fibers rise by ca. $85 \mathrm{~nm}$ above the surface. (G,H) Model for the secretion of spiral fibers. The upper panel in (G) corresponds to the non-secretional stage. When shell secretion resumes, the mantle cells recognize the positions of the tips of fibers in order to continue their secretion [lower panel in $\mathbf{( G ) ] . ~ ( H ) ~ I n ~ o r d e r ~ f o r ~ t h e ~ s p i r a l ~ p a t h ~ t o ~ b e ~ a c h i e v e d , ~ t h e ~ c e l l s ~ h a v e ~ t o ~ d i s p l a c e ~ t h e ~ t i p s ~ o f ~ t h e ~ f i b e r s ~ a l o n g ~ c i r c u l a r ~}$ trajectories. The displacement along the coiling axis is caused by the thickening of the shell. Arrows point to the external shell surface in (A-C), whereas they indicate the growth direction of fibers in (D-F). (E-H) Modified from Checa et al. (2016b).

calcite, despite its weakness, has developed independently in bivalves and gastropods. Even brachiopods and bryozoans have developed analogous calcitic foliated microstructures (see section "OTHER INVERTEBRATES"). The nacre 'solution' was reached independently by bivalves, gastropods, cephalopods, and monoplacophorans (Vendrasco et al., 2011). The probability that a given microstructure emerges seems to decrease when the organic influence increases. For example, the columnar prismatic layers are only found in two separate groups of bivalves, the subclasses Pteriomorphia (oysters, pearl oysters, pens shells, 


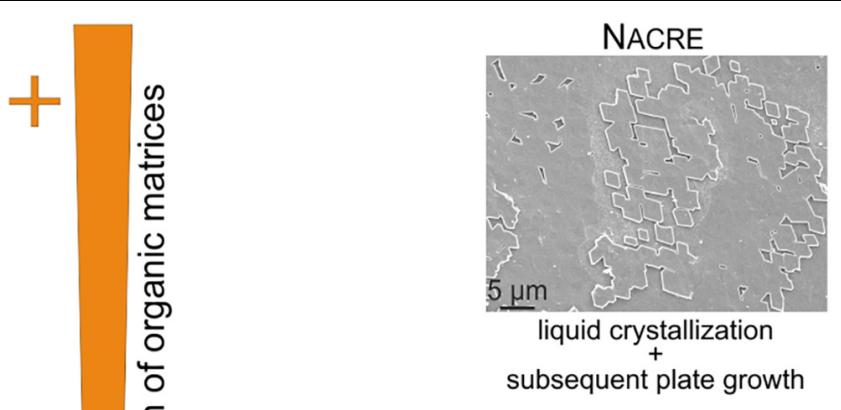

FIBROUS CALCITE

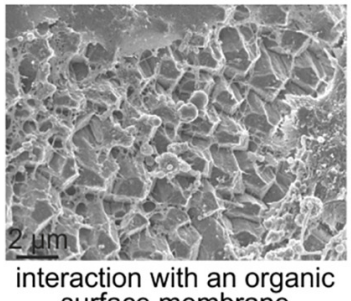

surface membrane

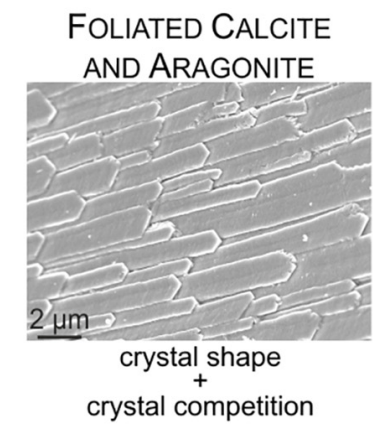

Columnar CALCite

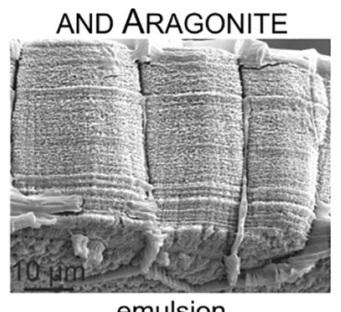

emulsion

$+$

contact recognition

differential subcellular secretion

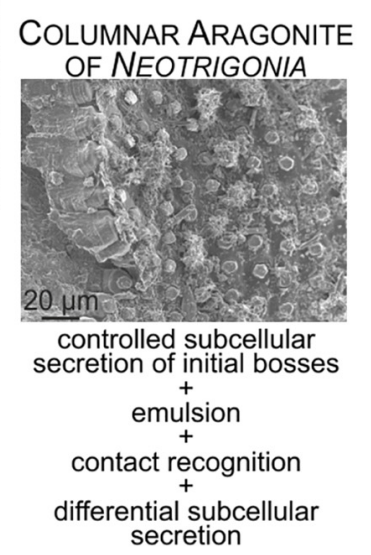

secretion

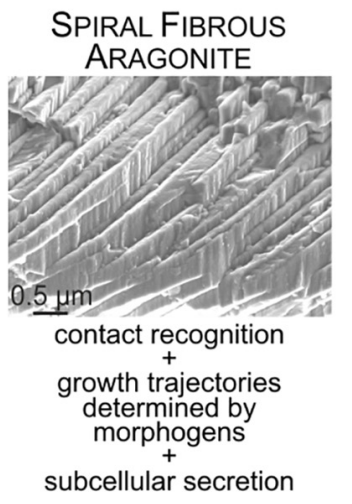

Direct subcellular activity

\section{Biological control}

FIGURE 10 | Approximate position of selected microstructures discussed in the text according to the physical and biological influences on their fabrication. In the columnar calcitic and aragonitic microstructures (including the columnar aragonitic microstructure of Neotrigonia), the aspects of calcite (with irregular outlines) and aragonite prisms (fibrous aggregates) suggest little to no control of the crystal shape. The microstructures represented correspond to the bivalves Pteria hirundo (nacre), Isognomon legumen (columnar prismatic calcite), Neotrigonia lamarckii (columnar prismatic aragonite), Mytilus galloprovincialis (fibrous calcite), Chama pellucida (prismatic, non-columnar, calcite) and Propeamussium dalli (foliated calcite), and to the gastropod Cuvierina columnella (helical fibrous aragonite).

some scallops) and Paleoheterodonta (naiads, Neotrigonia). The most extreme case of biological influence, the aragonitic helical fibrous microstructure, is only found in the Cavolinioidea, a small (52 species) and relatively recent (appeared $\sim 50 \mathrm{Ma}$ ago) group of planktonic gastropods. This evolutionary restriction might have to do with the high amount of genetic information necessary for its fabrication process, which is not the case of nacre, for example.

Unfortunately, there is currently no clear explanation for the fabrication of the crossed-lamellar microstructure, which is by far the most repeated microstructure during the evolution of molluscs and presently the most frequently occurring across the group. This characteristic suggests that, within the above evolutionary framework, the construction of the crossed-lamellar microstructure should be based rather on simple physical rules. Further knowledge on the fabrication of this microstructure will constitute a good test for our conclusions.

As commented on in the Introduction the dominant view some 10 years ago established that every aspect of the organization of the microstructures depended on the action of proteins and organic matrices. For example, the discussion of crystal orientation has traditionally focused on nacre, which is the classical example of a biomineral composed of oriented crystal tablets. Weiner and Traub $(1980,1984)$ proposed an epitaxial relationship between crystals and a preformed protein-chitin 


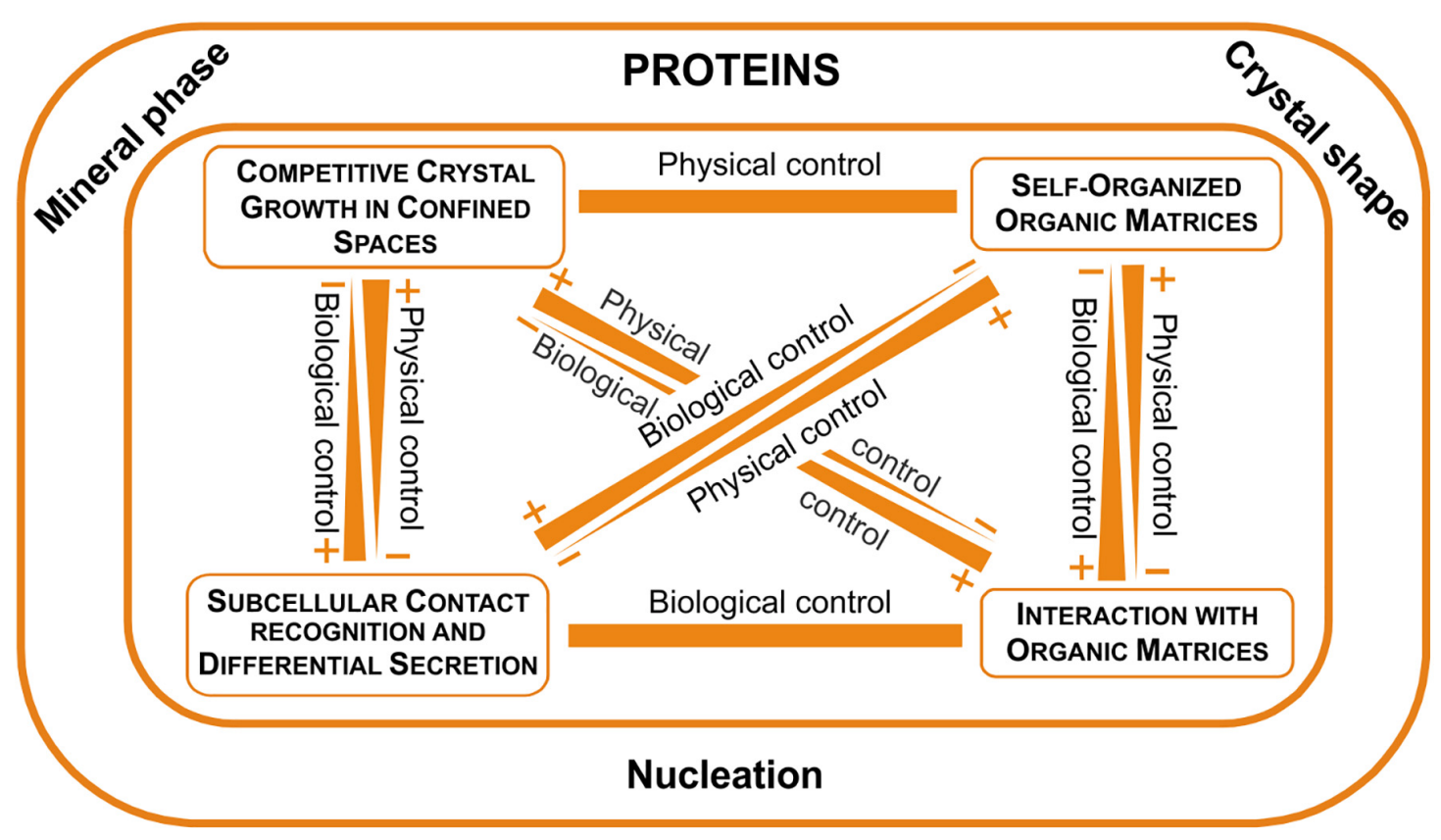

FIGURE 11 | The fabricational space of molluscan microstructures. Proteins clearly determine the mineral phase, crystal shape (with few exceptions) and nucleation, while other aspects of the fabrication process are determined by physical (crystal competition and self-organization), as well as biological determinants (interaction with organic matrices and direct cellular activity).

organic scaffold. This explanation stood until Nassif et al. (2005) revealed that nacre platelets are surrounded by a thin $(3-5 \mathrm{~nm})$ cortex of amorphous calcium carbonate which would make the epitaxial explanation impossible. Today, we know that nucleation is not even necessary for the initiation of nacre tablets, because tablets communicate across the lamellae through mineral bridges (Checa et al., 2011).

Our new view of the microstructures leads to a new fabricational framework according to which the soluble proteins determine the mineral phase and are responsible for crystal shape and nucleation. Other important aspects of the organization of microstructures are due to the interaction of crystals with organic matrices, the operation of self-organization mechanisms and the direct action of the mantle cells. Every microstructure would be organized according to a particular combination of these operators. All this is outlined in Figure 11.

\section{OTHER INVERTEBRATES}

Molluscs are exceptional among other biocalcifying taxa in two respects. First, they employ the two basic mineralogies: calcite and aragonite, and even combine them within a single shell. Second, they employ an unprecedented variety of calcitic and aragonitic microstructures as construction materials. Only bryozoans and serpulid polychaetes presently employ both mineralogies, but only the former make bimineralic shells.

Regarding the ability to control the fabrication of shell microstructures, groups such as scleractinian corals, serpulids and barnacles (Figures 12A-C) seem relatively unable to do that, since they secrete microstructures that are reminiscent of inorganic aggregates. Coral skeletons are made basically with aragonitic fibers radiating from calcification centers (Wendt, 1990; Nothdurft and Webb, 2007; Cuif et al., 2011; Figure 12A), thus being reminiscent of, for example, fibrous aragonitic cements. The microstructures of barnacles are virtually unknown, but our observations on the balanid Perforatus reveal that the plates are composed of calcite granules, sometimes with a neat rhombohedral morphology (Figure 12B), similar to any synthetic precipitate. Serpulids most commonly fabricate bimineralic tubes with fibrous (Figure 12C), prismatic or granular (sometimes rhombohedral) microstructures (Vinn et al., 2008; Vinn and Mutvei, 2009; Vinn, 2013). Some species secrete lamellofibrillar microstructures, which consist of horizontal lamellae of co-oriented fibers. In adjacent lamellae, fibers have different orientations, but similar to those of alternating lamellae. This arrangement is reminiscent of that of chiral nematic liquid crystals, i.e., it could be a case of a self-organized material. The absence of further evidence on the organization and the crystallographic structure of this material hinders any definite interpretation.

Lophophorates, bryozoans, and brachiopods secrete a large suite of calcitic microstructures (Williams, 1990, 1997; Taylor and Weedon, 2000; Taylor et al., 2015). Some cases display low degrees of organization, such as the granular microstructure of bryozoans or the fibrous primary layer of calcareous brachiopods, and they appear to be under little, if any, biological control. Other microstructures, such as the foliated microstructure (Figure 12D) and the semi-nacre (Figure 12E) are much more elaborate. The foliated microstructure is indistinguishable from that of molluscs 

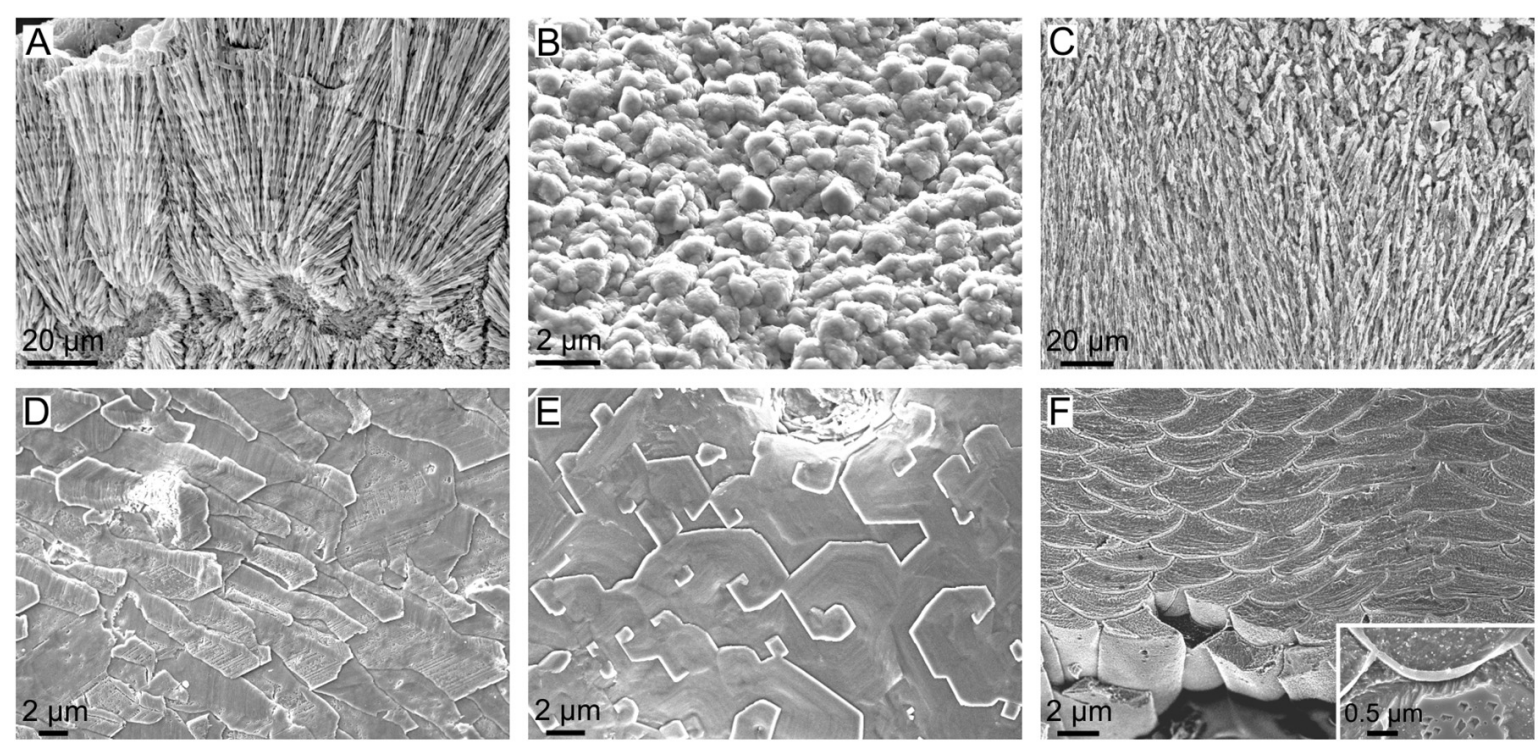

FIGURE 12 | Microstructures of calcifying invertebrates other than mollucs. (A) Fibrous aragonite of the scleractinian coral Goniastrea stelligera (etched fracture). (B) Calcitic granular microstructure of the balanomorph crustacean Perforatus perforatus (growth surface), Salobreña, Granada, Spain. (C) Aragonitic spherulitic prismatic structure of the serpulid polychaete Spiraserpula caribensis (polished and etched section), Netherlands Antilles, Curaçao. (D) Foliated calcite of the stenolaemata bryozoan Fasciculipora ramosa (growth surface), Australia. (E) Semi nacre of the cranioidea brachiopod Novocrania anomala (growth surface), Scotland. (F) Calcitic fibers of the secondary layer of the terebratulid brachiopod Laqueus rubellus (polished and etched section). Inset, close-up view of a similar fiber of the brachiopod Terebratalia transversa, showing the organic membranes between fibers.

and could be placed in the same position in the diagram of physical/biological determinants of Figure 10. The spiral growth of semi-nacre tablets is remarkable. It is similar to the spiral growth of nacre tablets of bivalves and, to a lesser extent, gastropods, which takes place when nacre tablets replicate the spiral defects previously formed in the interlamellar membranes (see subsection "The Interlamellar Membranes of Nacre"). In fact, Williams (1970) showed the existence of organic sheets, which he assumed to be proteins, between the tablets of the semi-nacre of Novocrania anomala. The semi-nacre sheets are thinner $(\sim 10 \mathrm{~nm})$ than the interlamellar membranes of nacre $(\sim 30 \mathrm{~nm})$, and nothing is known about their ultrastructure. In addition, spiral growth in semi-nacre affects only individual tablets (Figure 12E) and not big sets, as in nacre. Further ultrastructural evidence is needed in order to ascertain how the semi-nacre is organized. The only microstructure that might theoretically involve the direct action of the mantle cells is the calcitic fibrous microstructure, which constitutes the secondary layer of terebratulid brachiopods (e.g., Williams, 1997). It is made up of evenly sized and shaped, highly co-oriented calcitic fibers, each sheathed by a submicrometric organic membrane (Figure 12F). It also has a sharp crystallographic fiber texture (Schmahl et al., 2004). The uniform shapes of fibers and the persistent thicknesses of membranes around individual fibers imply that it is not simply a passive organic coating. The TEM sections of MacKinnon and Williams (1974) show that the mantle cells are in contact with the fibers through an extremely reduced extrapallial space, so that it is clear that they are actively producing such membranes. In view of the present evidence, the biological (cellular) control on the fabrication of this microstructure might be one of the highest among invertebrates.

\section{FINAL REMARKS}

The fabrication of microstructures is a complex process. With the increasing knowledge, it is becoming evident that molluscs can employ different strategies to fabricate different microstructures. Some of them are aimed at producing highly functional microstructures, as is the case of nacre. Why, despite its exceptional mechanical performance, nacre seems to have been losing ground in the benefit of other, less resistant microstructures, particularly the crossed lamellar, is unclear, but it has been related to the trade-off between mechanical performance and the metabolic cost of production (crossed lamellar is much cheaper to produce because of its relatively low organic content) (Palmer, 1983, 1992). But it is also possible that there is a phylogenetic aspect implied, i.e., the groups which have increased their diversity most dramatically during mollusc evolution (e.g., caenogastropods, heteroconch bivalves) are those traditionally secreting crossed lamellar layers. The demise of ammonoids at the end of the Cretaceous also dramatically reduced the diversity of nacreous cephalopods.

A particularly hot topic is the potential for marine organisms to adapt to increasing $\mathrm{CO}_{2}$ levels and the broad implications for ocean ecosystems; both are high priorities for future research. One well-known effect is the lowering of calcium carbonate saturation states, which impacts shell-forming marine organisms 
from plankton to benthic molluscs, echinoderms, and corals (e.g., Doney et al., 2009). Gazeau et al. (2013) provided a good summary of the results of studies dealing with the impacts of acidification on marine molluscs, including embryos and larvae. Many species of oysters, mussels, scallops, other bivalves, and some gastropods (including pteropods) become affected in several ways, which results in increased shell dissolution, reduced shell growth and several other physiological alterations. Particularly relevant to the topic covered in this review is a series of experimental studies (Hahn et al., 2012, 2014; Fitzer et al., 2014a,b, 2016), which have focused on microstructural changes under high $p \mathrm{CO}_{2}$, dealing with the outer fibrous layer of two species of Mytilus, M. galloprovincialis and $M$. edulis. All of them found that the otherwise highly oriented fibers (Figure 6A) became locally disorganized. Subsequent EBSD analyses demonstrated that the 001 pole figures showed a bimodal or multi-modal distribution, instead of a single, low-spread maximum, typical of shells grown in normal conditions (Figure 6B). Accordingly, the animals exerted less crystallographic control under high$\mathrm{CO}_{2}$ conditions. McCoy et al. (2017) also applied EBSD to the outer calcitic fibrous layers of shells of $M$. californianus dating from the present to $2440 \mathrm{BP}$. They found evidence for consistent mineral structure in $M$. californianus over the preceding 2500 years, except for the most recent samples (from 2010 to 2015), which showed greater disorder among crystals and smaller crystal sizes. Thus, they provided historical evidence that crystallographic control diminished in coincidence with increasing ocean acidification. Regrettably, these studies do not reveal which element or elements of the fabricational system (e.g., periostracum, surface membrane, organic sheaths around fibers; see subsection "Orientation by Interaction With Organic Matrices") became altered due to increasing acidification. This knowledge is essential in studies about the impact of global climatic change on biomineralization. An additional point of interest is to estimate the correlation between the degree of physical/biological control on particular microstructures and their susceptibility to increasing acidification levels.

The knowledge of the fabricational strategies of molluscan microstructures is essential, for instance, for future biomimetic

\section{REFERENCES}

Addadi, L., Moradian, J., Shay, E., Maroudas, N. G., and Weiner, S. (1987). A chemical model for the cooperation of sulfates and carboxylates in calcite crystal nucleation: Relevance to biomineralization. Proc. Natl. Acad. Sci. U.S.A. 84, 2732-2736. doi: 10.1073/pnas.84.9.2732

Almagro, I., Drzymała, P., Berent, K., Sainz-Díaz, C. I., Willinger, M. G., Bonarski, J., et al. (2016). New crystallographic relationships in biogenic aragonite: the crossed-lamellar microstructures of mollusks. Cryst. Growth Des. 16, 2083-2093. doi: 10.1021/acs.cgd.5b01775

Andrienko, D. (2018). Introduction to liquid crystals. J. Mol. Liquids (in press). doi: 10.1016/j.molliq.2018.01.175

Appeltans, W., Ahyong, S. Y., Anderson, G., Angel, M. V., Artois, T., Bailly, N., et al. (2012). The magnitude of global marine species diversity. Curr. Biol. 22, 2189-2202. doi: 10.1016/j.cub.2012.09.036

Baronnet, A., Cuif, J. P., Dauphin, Y., Farre, B., and Nouet, J. (2008). Crystallization of biogenic Ca-carbonate within organo-mineral micro-domains. Structure of studies, which aim at using the biofabrication strategies as inspiration. As with the probability of a particular microstructure to evolve convergently, those microstructures based on physical principles (which can eventually be reproduced in the laboratory) will have a better chance to be biomimetized in the future than those in which a complex subcellular activity is an essential part of the fabrication process.

\section{AUTHOR CONTRIBUTIONS}

The author confirms being the sole contributor of this work and approved it for publication.

\section{FUNDING}

AC received funding from Project CGL2013-48247-P and CGL2017-85118-P of the Spanish Ministerio de Economía $y$ Competitividad (MINECO) and the Fondo Europeo de Desarrollo Regional (FEDER), from the Research Group RNM363 (Consejería de Economía, Innovación, Ciencia y Empleo of the Junta de Andalucía) and from the Unidad Científica de Excelencia UCE-PP2016-05 of the University of Granada.

\section{ACKNOWLEDGMENTS}

Particular thanks are given to my friends and collaborators Julyan H. E. Cartwright (Instituto Andaluz de Ciencias de la Tierra, CSIC-Universidad de Granada, Armilla, Spain) and Elizabeth M. Harper (Department of Earth Sciences, University of Cambridge, United Kingdom) for sharing their knowledge on physical selforganization and on the diversity of molluscan microstructures. The following colleagues kindly provided images: Elizabeth M. Harper, University of Cambridge, United Kingdom (Figure 1G), Jalosław Stolarski, University of Warsaw, Poland (Figure 12A), Olev Vinn, University of Tartu, Estonia (Figure 12C), Erika Griesshaber, Ludwig Maximilian University, Munich, Germany (Figure 12F, including the inset).

the calcite prisms of the Pelecypod Pinctada margaritifera (Mollusca) at the submicron to nanometre ranges. Mineral. Mag. 72, 617-626. doi: 10.1180/ minmag.2008.072.2.617

Bayerlein, B., Zaslansky, P., Dauphin, Y., Rack, A., Fratzl, P., and Zlotnikov, I. (2014). Self-similar mesostructure evolution of the growing mollusc shell reminiscent of thermodynamically driven grain growth. Nat. Mater. 13, 11021107. doi: $10.1038 /$ nmat 4110

Bé, A. W. H., MacClintock, C., and Currie, D. C. (1972). Helical shell structure and growth of the pteropod Cuvierina columnella (Rang) (Mollusca, Gastropoda). Biomineralization. Res. Rep. 4, 47-79.

Belcher, A. M., Wu, X. H., Christensen, R. J., Hansma, P. K., Stucky, G. D., and Morse, D. E. (1996). Control of crystal phase switching and orientation by soluble mollusc-shell proteins. Nature 381, 56-58. doi: 10.1038/381056a0

Berman, A., Hanson, J., Leiserowitz, L., Koetzle, T. F., Weiner, S., and Addadi, L. (1993). Biological control of crystal texture: a widespread strategy for adapting crystal properties to function. Science 259, 776-779. doi: 10.1126/science.259. 5096.776 
Bevelander, G., and Nakahara, H. (1969). An electron microscope study of the formation of the nacreous layer in the shell of certain bivalve molluscs. Calcif. Tissue Res. 3, 84-92. doi: 10.1007/BF02058648

Bouligand, Y. (1972). Twisted fibrous arrangements in biological materials and cholesteric mesophases. Tissue Cell 4, 189-217. doi: 10.1016/S0040-8166(72) 80042-9

Carter, J. G., Harries, P. J., Malchus, N., Sartori, A. F., Anderson, L. C., Bieler, R., et al. (2012). Illustrated Glossary of the Bivalvia: Treatise Online, part N, Revised, Vol. 1, Chap. 31. Lawrence, KS: Kansas University Paleontological Institute, $1-209$.

Cartwright, J. H. E., and Checa, A. G. (2007). The dynamics of nacre self-assembly. J. R. Soc. Interface 4, 491-504. doi: 10.1098/rsif.2006.0188

Cartwright, J. H. E., Checa, A. G., Escribano, B., and Sainz-Díaz, C. I. (2009). Spiral and target patterns in bivalve nacre manifest a natural excitable medium from layer growth of a biological liquid crystal. Proc. Natl. Acad. Sci. U.S.A. 106, 10499-10504. doi: 10.1073/pnas.0900867106

Chateigner, D., Hedegaard, C., and Wenk, H. R. (2000). Mollusc shell microstructures and crystallographic textures. J. Struct. Geol. 22, 1723-1735. doi: 10.1016/S0191-8141(00)00088-2

Checa, A. G., Cartwright, J. H. E., Sánchez-Almazo, I., Andrade, J. P., and Ruiz-Raya, F. (2015). The cuttlefish Sepia officinalis (Sepiidae, Cephalopoda) constructs cuttlebone from a liquid-crystal precursor. Sci. Rep. 5:11513. doi: $10.1038 /$ srep 11513

Checa, A. G., Cartwright, J. H. E., and Willinger, M. G. (2009a). The key role of the surface membrane in why gastropod nacre grows in towers. Proc. Natl. Acad. Sci. U.S.A. 106, 38-43. doi: 10.1073/pnas.0808796106

Checa, A. G., Cartwright, J. H. E., and Willinger, M. G. (2011). Mineral bridges in nacre. J. Struct. Biol. 176, 330-339. doi: 10.1016/j.jsb.2011.09.011

Checa, A. G., Esteban-Delgado, F. J., and Rodríguez-Navarro, A. B. (2007). Crystallographic structure of the foliated calcite of bivalves. J. Struct. Biol. 157, 393-402. doi: 10.1016/j.jsb.2006.09.005

Checa, A. G., and Harper, E. M. (2010). Spikey bivalves: intra-periostracal crystal growth in anomalodesmatans. Biol. Bull. 219, 231-248. doi: 10.1086/ BBLv219n3p231

Checa, A. G., Harper, E. M., and González-Segura, A. (2018). Structure and crystallography of foliated and chalk shell microstructures of the oyster Magallana: the same materials grown under different conditions. Sci. Rep. 8:7507. doi: 10.1038/s41598-018-25923-6

Checa, A. G., Macías-Sánchez, E., Harper, E. M., and Cartwright, J. H. E. (2016a). Organic membranes determine the pattern of the columnar prismatic layer of mollusc shells. Proc. R. Soc. B 283:20160032. doi: 10.1098/rspb. 2016.0032

Checa, A. G., Macías-Sánchez, E., and Ramírez-Rico, J. (2016b). Biological strategy for the fabrication of highly ordered aragonite helices: the microstructure of the cavolinioidean gastropods. Sci. Rep. 6:25989. doi: 10.1038/srep25989

Checa, A. G., Okamoto, T., and Ramírez, J. (2006). Organisation pattern of nacre in Pteriidae (Bivalvia: Mollusca) explained by crystal competition. Proc. R. Soc. B 273, 1329-1337. doi: 10.1098/rspb.2005.3460

Checa, A. G., Pina, C. M., Osuna-Mascaró, A. J., Rodríguez-Navarro, A. B., and Harper, E. M. (2014a). Crystalline organization of the fibrous prismatic calcitic layer of the Mediterranean mussel Mytilus galloprovincialis. Eur. J. Mineral. 26, 495-505. doi: 10.1127/0935-1221/2014/0026-2374

Checa, A. G., Ramírez-Rico, J., González-Segura, A., and Sánchez-Navas, A. (2009b). Nacre and false nacre (foliated aragonite) in extant monoplacophorans (= Tryblidiida: Mollusca). Naturwissenschaften 96, 111-122. doi: 10.1007/ s00114-008-0461-1

Checa, A. G., and Rodríguez-Navarro, A. (2001). Geometrical and crystallographic constraints determine the self-organization of shell microstructures in Unionidae (Bivalvia: Mollusca). Proc. R. Soc. B 268, 771-778. doi: 10.1098/rspb. 2000.1415

Checa, A. G., Rodríguez-Navarro, A. B., and Esteban-Delgado, F. J. (2005). The nature and formation of calcitic columnar prismatic shell layers in pteriomorphian bivalves. Biomaterials 26, 6404-6414. doi: 10.1016/j. biomaterials.2005.04.016

Checa, A. G., and Salas, C. (2017). Periostracum and shell formation in the Bivalvia: Treatise Online, part N, Revised, Vol. 1, Chap. 3. Lawrence, K: Kansas University Paleontological Institute, 1-51.
Checa, A. G., Salas, C., Harper, E. M., and Bueno-Pérez, J. D. (2014b). Early stage biomineralization in the periostracum of the 'living fossil' bivalve Neotrigonia. PLoS One 9:e90033. doi: 10.1371/journal.pone.0090033

Checa, A. G., Sánchez-Navas, A., and Rodríguez-Navarro, A. B. (2009c). Crystal growth in the foliated aragonite of monoplacophorans (Mollusca). Cryst. Growth Des. 9, 4574-4580. doi: 10.1021/cg9005949

Crenshaw, M. A. (1972). The inorganic composition of molluscan extrapallial fluid. Biol. Bull. 143, 506-512. doi: 10.2307/1540180

Cuif, J. P., Dauphin, Y., and Sorauf, J. E. (2011). Biominerals and Fossils through Time. Cambridge: Cambridge University Press.

Cusack, M., and Freer, A. (2008). Biomineralization: elemental and organic influence in carbonate systems. Chem. Rev. 108, 4433-4454. doi: 10.1021/ cr078270o

Doney, S. C., Fabry, V. J., Feely, R. A., and Kleypas, J. A. (2009). Ocean acidification: the other $\mathrm{CO}_{2}$ problem. Annu. Rev. Mar. Sci. 1, 169-192. doi: 10.1146/annurev. marine.010908.163834

Falini, G., Albeck, S., Weiner, S., and Addadi, L. (1996). Control of aragonite or calcite polymorphism by mollusk shell macromolecules. Science 271, 67-69. doi: 10.1126/science.271.5245.67

Fitzer, S. C., Chung, P., Maccherozzi, F., Dhesi, S. S., Kamenos, N. A., Phoenix, V. R., et al. (2016). Biomineral shell formation under ocean acidification: a shift from order to chaos. Sci. Rep. 6:21076. doi: 10.1038/srep21076

Fitzer, S. C., Cusack, M., Phoenix, V. R., and Kamenos, N. A. (2014a). Ocean acidification reduces the crystallographic control in juvenile mussel shells. J. Struct. Biol. 188, 39-45. doi: 10.1016/j.jsb.2014.08.007

Fitzer, S. C., Phoenix, V. R., Cusack, M., and Kamenos, N. A. (2014b). Ocean acidification impacts mussel control on biomineralisation. Sci. Rep. 4:6218. doi: 10.1038/srep06218

Gazeau, F., Parker, L. M., Comeau, S., Gattuso, J.-P., O'Connor, W. A., Martin, S., et al. (2013). Impacts of ocean acidification on marine shelled molluscs. Mar. Biol. 160, 2207-2245. doi: 10.1007/s00227-013-2219-3

Gower, L. B. (2008). Biomimetic model systems for investigating the amorphous precursor pathway and its role in biomineralization. Chem. Rev. 108, 45514627. doi: $10.1021 / \mathrm{cr} 800443 \mathrm{~h}$

Hahn, S., Griesshaber, E., Schmahl, W. W., Neuser, R. D., Ritter, A.-C., Hoffmann, R., et al. (2014). Exploring aberrant bivalve shell ultrastructure and geochemistry as proxies for past sea water acidification. Sedimentology 61 , 1625-1658. doi: 10.1111/sed.12107

Hahn, S., Rodolfo-Metalpa, R., Griesshaber, E., Schmahl, W. W., Buhl, D., Hall-Spencer, J. M., et al. (2012). Marine bivalve shell geochemistry and ultrastructure from modern low $\mathrm{pH}$ environments: environmental effect versus experimental bias. Biogeoscience 9, 1897-1914. doi: 10.5194/bg-9-1897-2012

Hare, P. E., and Abelson, P. H. (1965). Amino acid composition of some calcified proteins. Carnegie Inst. Washington Year Book 64, 223-232.

Harper, E. M., and Checa, A. G. (2017). Physical versus biological control in bivalve calcite prisms: comparison of euheterodonts and pteriomorphs. Biol. Bull. 232, 19-29. doi: $10.1086 / 691382$

Harper, E. M., Checa, A. G., and Rodríguez-Navarro, A. B. (2009). Organization and mode of secretion of the granular prismatic microstructure of Entodesma navicula (Bivalvia: Mollusca). Acta Zool. 90, 132-141. doi: 10.1111/j.1463-6395. 2008.00338.x

Hedegaard, C., and Wenk, H.-R. (1998). Microstructure and texture patterns of mollusc shells. J. Molluscan Stud. 64, 133-136. doi: 10.1093/mollus/64.1.133

Kobayashi, S. (1964b). Studies in shell formation. X. A study of the proteins of the extrapallial fluid in some molluscan species. Biol. Bull. 126, 414-422. doi: $10.2307 / 1539310$

Kobayashi, S. (1964a). Calcification in fish and shellfish. II. A paper electrophoretic study on the acid mucopolysaccharides and PAS-positive materials of the extrapallial fluid in some molluscan species. Bull. Jpn. Soc. Sci. Fish. 30, 893-907. doi: 10.2331 /suisan. 30.893

Korringa, P. (1951). On the nature and function of "chalky" deposits in the shell of Ostrea edulis Linnaeus. Proc. Calif. Acad. Sci. 27, 133-158.

Levi-Kalisman, Y., Falini, G., Addadi, L., and Weiner, S. (2001). Structure of the nacreous organic matrix of a bivalve mollusk shell examined in the hydrated state using cryo-TEM. J. Struct. Biol. 135, 8-17. doi: 10.1006/jsbi.2001.4372

Lowenstam, H. A. (1981). Minerals formed by organisms. Science 211, 1126-1131. doi: $10.1126 /$ science. 7008198 
Lowenstam, H. A., and Weiner, S. (1989). On Biomineralization. New York, NY: Oxford University Press.

Ma, H. Y., and Lee, I. S. (2006). Characterization of vaterite in low quality freshwater-cultured pearls. Mater. Sci. Eng. C 26, 721-723. doi: 10.1016/j.msec. 2005.09.109

Macías-Sánchez, E., Willinger, M. G., Pina, C. M., and Checa, A. G. (2017). Transformation of ACC into aragonite and the origin of the nanogranular structure of nacre. Sci. Rep. 7:12728. doi: 10.1038/s41598-017-12673-0

MacKinnon, D. I., and Williams, A. (1974). Shell structure of terebratulid brachiopods. Palaeontology 17, 179-202.

Mann, S. (1983). Mineralization in biological systems. Struct. Bonding 54, 125-174. doi: $10.1007 / \mathrm{BFb} 0111316$

Marin, F., Luquet, G., Marie, B., and Medakovic, D. (2008). Molluscan shell proteins: primary structure, origin, and evolution. Curr. Top. Dev. Biol. 80, 209-276. doi: 10.1016/S0070-2153(07)80006-8

McCoy, S. J., Kamenos, N. A., Chung, P., Wootton, T. J., and Pfister, C. A. (2017). A mineralogical record of ocean change: decadal and centennial patterns in the California mussel. Global Change Biol. 24, 2554-2562. doi: 10.1111/gcb.14013

Misogianes, M. J., and Chasteen, N. D. (1979). A chemical and spectral characterization of the extrapallial fluid of Mytilus edulis. Anal. Biochem. 100, 324-334. doi: 10.1016/0003-2697(79)90236-7

Moysiuk, J., Smith, M. R., and Caron, J. B. (2017). Hyoliths are Palaeozoic lophophorates. Nature 541, 394-397. doi: 10.1038/nature20804

Mullins, W. W. (1956). Two-dimensional motion of idealized grain boundaries. J. Appl. Phys. 27, 900-904. doi: 10.1063/1.1722511

Nakahara, H. (1991). "Nacre formation in bivalve and gastropod mollusks," in Mechanisms and Phylogeny of Mineralization in Biological Systems, eds S. Suga and H. Nakahara (Berlin: Springer), 343-350. doi: 10.1007/978-4-431-681 32-8_55

Nakahara, H., and Bevelander, G. (1971). The formation and growth of the prismatic layer of Pinctada radiata. Calcif. Tissue Res. 7, 31-45. doi: 10.1007/ BF02062591

Nassif, N., Pinna, N., Gehrke, N., Antonietti, M., Jäger, C., and Cölfen, H. (2005). Amorphous layer around aragonite platelets in nacre. Proc. Natl. Acad. Sci. U.S.A. 102, 12653-12655. doi: 10.1073/pnas.0502577102

Nehrke, G., Poigner, H., Wilhelms-Dick, D., Brey, T., and Abele, D. (2012). Coexistence of three calcium carbonate polymorphs in the shell of the Antarctic clam Laternula elliptica. Geochem. Geophys. Geosyst. 13:Q05014. doi: 10.1029/ 2011GC003996

Neville, A. C. (1993). Biology of Fibrous Composites. Cambridge: Cambridge University Press. doi: 10.1017/CBO9780511601101

Nothdurft, L. D., and Webb, G. E. (2007). Microstructure of common reefbuilding coral genera Acropora, Pocillopora, Goniastrea and Porites: constraints on spatial resolution in geochemical sampling. Facies 53, 1-26. doi: 10.1007/ s10347-006-0090-0

Nudelman, F., Chen, H. H., Goldberg, H. A., Weiner, S., and Addadi, L. (2007). Lessons from biomineralization: comparing the growth strategies of mollusc shell prismatic and nacreous layers in Atrina rigida. Faraday Discuss. 136, 9-25. doi: $10.1039 / \mathrm{B} 704418 \mathrm{~F}$

Osuna-Mascaró, A. J., Cruz-Bustos, T., Marin, F., and Checa, A. G. (2015). Ultrastructure of the interlamellar membranes of the nacre of the bivalve Pteria hirundo, determined by immunolabelling. PLoS One 10:e0122934. doi: 10.1371/ journal.pone.0122934

Palmer, A. R. (1983). Relative cost of producing skeletal organic matrix versus calcification: evidence from marine mollusks. Mar. Biol. 75, 287-292. doi: 10. 1007/BF00406014

Palmer, A. R. (1992). Calcification in marine molluscs: how costly is it? Proc. Natl. Acad. Sci. U.S.A. 89, 1379-1382. doi: 10.1073/pnas.89.4.1379

Pereira-Mouriès, L., Almeida, M. J., Ribeiro, C., Peduzzi, J., Barthélemy, M., Milet, C., et al. (2002). Soluble silk-like organic matrix in the nacreous layer of the bivalve Pinctada maxima. A new insight in the biomineralization field. Eur. J. Biochem. 269, 4994-5003. doi: 10.1046/j.1432-1033.2002.03203.x

Pietrzak, J. E., Bates, J. M., and Scott, R. M. (1973). Constituents of unionid extrapallial fluid. I. Electrophoretic and immunological studies of protein components. Biol. Bull. 144, 391-399. doi: 10.2307/1540016

Schäffer, T. E., Ionescu-Zanetti, C., Proksch, R., Fritz, M., Walters, D. A., Almquist, N., et al. (1997). Does abalone nacre form by heteroepitaxial nucleation or by growth through mineral bridges? Chem. Mater. 9, 1731-1740. doi: $10.1021 / \mathrm{cm} 960429 \mathrm{i}$

Schenk, A. S., Zope, H., Kim, Y. Y., Kros, A., Sommerdijk, N. A. J. M., and Meldrum, F. C. (2012). Polymer-induced liquid precursor (PILP) phases of calcium carbonate formed in the presence of synthetic acidic polypeptidesrelevance to biomineralization. Faraday Discuss. 159, 327-344. doi: 10.1039/ c2fd20063e

Schmahl, W. W., Griesshaber, E., Neuser, R., Lenze, A., Job, R., and Brand, U. (2004). The microstructure of the fibrous layer of terebratulide brachiopod shell calcite. Eur. J. Mineral. 16, 693-697. doi: 10.1127/0935-1221/2004/00160693

Spann, N., Harper, E. M., and Aldridge, D. C. (2010). The unusual mineral vaterite in shells of the freshwater bivalve Corbicula fluminea from the UK. Naturwissenschaften 97, 743-751. doi: 10.1007/s00114-010-0692-9

Stevens, K., Griesshaber, E., Schmahl, W., Casella, L. A., Iba, Y., and Mutterlose, J. (2017). Belemnite biomineralization, development, and geochemistry: the complex rostrum of Neohibolites minimus. Palaeogeogr. Palaeoclimatol. Palaeoecol. 468, 388-402. doi: 10.1016/j.palaeo.2016.12.022

Taylor, J. D., Glover, E. A., and Braithwaite, C. J. R. (1999). Bivalves with 'concrete overcoats': Granicorium and Samarangia. Acta Zool. 80, 285-300. doi: 10.1046/ j.1463-6395.1999.00019.x

Taylor, P. D., Lombardi, C., and Cocito, S. (2015). Biomineralization in bryozoans: present, past and future. Biol. Rev. 90, 1118-1150. doi: 10.1111/brv.12148

Taylor, P. D., and Weedon, M. J. (2000). Skeletal ultrastructure and phylogeny of cyclostome bryozoans. Zool. J. Linn. Soc. 128, 337-399. doi: 10.1006/zjls.1999. 0195

Ubukata, T. (1994). Architectural constraints of the morphogenesis of prismatic structures in Bivalvia. Palaeontology 37, 241-261.

Vendrasco, M. J., Checa, A. G., and Kouchinsky, A. V. (2011). Shell microstructure of the early bivalve Pojetaia and the independent origin of nacre within the mollusca. Palaeontology 54, 825-850. doi: 10.1111/j.1475-4983.2011. 01056.x

Vinn, O. (2013). Occurrence, formation and function of organic sheets in the mineral tube structures of Serpulidae (Polychaeta, Annelida). PLoS One 8:e75330. doi: 10.1371/journal.pone.0075330.g001

Vinn, O., and Mutvei, H. (2009). Calcareous tubeworms of the Phanerozoic. Estonian J. Earth Sci. 58, 286-296. doi: 10.3176/earth.2009.4.07

Vinn, O., Ten Hobe, H. A., Mutvei, H., and Kirsimäe, K. (2008). Ultrastructure and mineral composition of serpulid tubes (Polychaeta, Annelida). Zool. J. Linn. Soc. 154, 633-650. doi: 10.1111/j.1096-3642.2008.00421.x

von Neumann, J. (1952). "Written discussion on a paper of C. S. Smith," in Metal Interfaces, ed. C. Herring (Cleveland, OH: American Society of Metals), 108-110.

Wada, K., and Fujinuki, T. (1976). "Biomineralization in bivalve molluscs with emphasis on the chemical composition of the extrapallial fluid," in Mechanisms of Mineralization in the Invertebrates and Plants, eds N. Watabe and K. M. Wilbur (Columbia, SC: University of South Carolina Press), 175-190.

Wehrmeister, U., Jacob, D. E., Soldati, A. L., Häger, T., and Hofmeister, W. (2007). Vaterite in freshwater cultured pearls from China and Japan. J. Gemmol. 31, 269-276. doi: 10.15506/JoG.2007.30.7.399

Weiner, S., and Addadi, L. (1997). Design strategies in mineralized biological materials. J. Mater. Chem. 7, 689-702. doi: 10.1039/A604512J

Weiner, S., and Dove, P. M. (2003). An overview of biomineralization processes and the problem of the vital effect. Rev. Mineral. Geochem. 54, 1-29. doi: $10.2113 / 0540001$

Weiner, S., and Traub, W. (1980). X-ray diffraction study of the insoluble organic matrix of mollusk shells. FEBS Lett. 111, 311-316. doi: 10.1016/0014-5793(80) 80817-9

Weiner, S., and Traub, W. (1984). Macromolecules in mollusk shells and their functions in biomineralization. Phil. Trans. R. Soc. B 304, 425-434. doi: 10.1098/ rstb.1984.0036

Wendt, J. (1990). "Corals and coralline sponges," in Skeletal Biomineralization: Patterns, Processes and Evolutionary Trends, Vol. 1, ed. J. G. Carter (New York, NY: Van Nostrand Reinhold), 45-66.

Wilbur, K. M., and Saleuddin, A. S. M. (1983). "Shell formation," in The Mollusca, Vol. 4, Part 1, eds A. S. M. Saleuddin and K. M. Wilbur (New York, NY: Academic Press), 235-287. 
Wilbur, K. M., and Simkiss, K. (1968). "Calcified shells," in Comprehensive Biochemistry, Vol. 26A, eds M. Florkin and E. H. Stotz (New York, NY: Elsevier), 229-295.

Williams, A. (1970). Spiral growth of the laminar shell of the brachiopod Crania. Calcif. Tissue Res. 6, 11-19. doi: 10.1007/BF02196180

Williams, A. (1990). "Biomineralization in the lophophorates," in Skeletal Biomineralization: Patterns, Processes and Evolutionary Trends, Vol. 1, ed. J. G. Carter (New York, NY: Van Nostrand Reinhold), 67-82.

Williams, A. (1997). "Shell structures," in Treatise on Invertebrate Paleontology, Part H, Brachiopoda Revised, eds A. Williams, C. H. C. Brunton, and S. J. Carlson (Lawrence, K: University Press of Kansas), 267-320.

Willinger, M. G., Checa, A. G., Bonarski, J. T., Faryna, M., and Berent, K. (2016). Biogenic crystallographically continuous aragonite helices: the microstructure of the planktonic gastropod Cuvierina. Adv. Funct. Mater. 26, 553-561. doi: 10.1002/adfm.201504034

Conflict of Interest Statement: The author declares that the research was conducted in the absence of any commercial or financial relationships that could be construed as a potential conflict of interest.

Copyright $\odot 2018$ Checa. This is an open-access article distributed under the terms of the Creative Commons Attribution License (CC BY). The use, distribution or reproduction in other forums is permitted, provided the original author(s) and the copyright owner(s) are credited and that the original publication in this journal is cited, in accordance with accepted academic practice. No use, distribution or reproduction is permitted which does not comply with these terms. 